\title{
La Phocide protohistorique : recherches archéologiques et géoarchéologiques sur le tell de Kirrha et dans la plaine d'Itea (Grèce) - 2019
}

Raphaël Orgeolet, Camille Bouffiès, Anne-Zahra Chemsseddoha, Marie De Jonghe, Maria Katsimicha, Laetitia Laquay, Rodolphe Martinez, Adèle Vorsanger et + Simon Sedlbauer

\section{(2) OpenEdition}

\section{Édition électronique}

URL : http://journals.openedition.org/baefe/1413

DOI : 10.4000/baefe.1413

ISSN : 2732-687X

Éditeur

ResEFE

\section{Référence électronique}

Raphaël Orgeolet, Camille Bouffiès, Anne-Zahra Chemsseddoha, Marie De Jonghe, Maria Katsimicha, Laetitia Laquay, Rodolphe Martinez, Adèle Vorsanger et † Simon Sedlbauer, « La Phocide protohistorique : recherches archéologiques et géoarchéologiques sur le tell de Kirrha et dans la plaine d'Itea (Grèce) - 2019 » [notice archéologique], Bulletin archéologique des Écoles françaises à l'étranger [En ligne], Grèce, mis en ligne le 26 novembre 2020, consulté le 22 mars 2021. URL : http:// journals.openedition.org/baefe/1413; DOI : https://doi.org/10.4000/baefe.1413

Ce document a été généré automatiquement le 22 mars 2021.

Le Bulletin archéologique des Écoles françaises à l'étranger est mise à disposition selon les termes de la Licence Creative Commons Attribution - Pas d'Utilisation Commerciale - Pas de Modification 4.0 International. 


\title{
La Phocide protohistorique : recherches archéologiques et géoarchéologiques sur le tell de Kirrha et dans la plaine d'Itea (Grèce) - 2019
}

\author{
Raphaël Orgeolet, Camille Bouffiès, Anne-Zahra Chemsseddoha, Marie \\ De Jonghe, Maria Katsimicha, Laetitia Laquay, Rodolphe Martinez, Adèle \\ Vorsanger et + Simon Sedlbauer
}

\section{NOTE DE L'AUTEUR}

Autorité nationale présente : Nikolaos Petrocheilos, Éphorie de Delphes Numéro de mission : D31

Composition de l'équipe de terrain : Clémence Pagnoux et Evi Margaritis pour la carpologie ; Kalliope Sarri pour l'étude de la céramique ; Camille Bouffiès, Anne-Zahra Chemsseddoha, Marie De Jonghe, Maria Katsimicha et Laetitia Laquay pour la fouille des sépultures et des espaces funéraires ; Marie Floquet pour le développement du SIG de site ; Lionel Fadin et Emma Richard pour la topographie : Aristophanis Konstantatos et Katerina Liliou pour la restauration de la céramique ; Lucille Garnery était en charge de l'apothèque et du dessin de céramique. La conduite des opérations de fouille s'est faite sous la direction de Rodolphe Martinez, $\uparrow$ Simon Sedlbauer et Adèle Vorsanger. Les étudiants stagiaires en archéologie, anthropologie et carpologie étaient : Louise Cortès, Cilia Fasianou, Lara Fleury, Jeanne His, Sarah Lafolie, Valentin Loescher, MariaPia Morico, Louis Pirat, Edson Poiati, Jérémy Sicard, Anastasia Solomos, Léo Tillard, Alexandra Vauzelle et Ismini Venetatou.

Partenariats institutionnels : École française d'Athènes, Ministère de l'Europe et des Affaires Étrangères, Institute for Aegean Prehistory, Aix Marseille Université 
Établissements porteurs de l'opération : EFA, MEAE

Remerciements : Ce rapport est dédié à la mémoire de notre collègue et ami Simon Sedlbauer, disparu quelques mois après la mission.

Données scientifiques produites :

Kirrha par EFA

Chroniques de l'EfA :

Kirrha 2018

1 La mission tient tout particulièrement à remercier les collègues de l'Éphorie des Antiquités de Delphes, dont notamment Athanasia Psalti (directrice) et Nikolaos Petrocheilos (archéologue). Nos remerciements vont également à nos hôtes, les habitants de Kirrha.

2 La campagne de terrain 2019 s'est déroulée à Kirrha durant 6 semaines, du 24 juillet au 2 août. En raison de la baisse significative de nos crédits, les opérations ont été limitées cette année à deux secteurs (secteur 2-3-5 en zone PA et secteur 4 en zone NE, cf. fig. 3) ; les objectifs étaient les suivants :

- dans le secteur 2-3-5, il convenait d'une part de terminer la fouille des contextes funéraires de la nécropole HM III - HR I/II et d'autre part de poursuivre l'exploration des vestiges d'habitat HM mis au jour dans la partie SE du secteur depuis 2014 ;

- dans le secteur 4, il s'agissait de fouiller la grande tombe à ciste protomyécnienne dégagée en 2018 (L950), ainsi que d'explorer les niveaux d'habitat de l'HR I apparus la même année dans la partie Est du secteur.

3 L'ensemble de ces objectifs a été atteint, avec notamment la fouille complète de 15 contextes funéraires et l'exploration des niveaux d'habitat ciblés.

\section{Le secteur 4}

Camille Bouffiès, Rodolphe Martinez et Adèle Vorsanger 
Fig. 1. Plan général du secteur 4.

Kirrha 2019 - Secteur 4

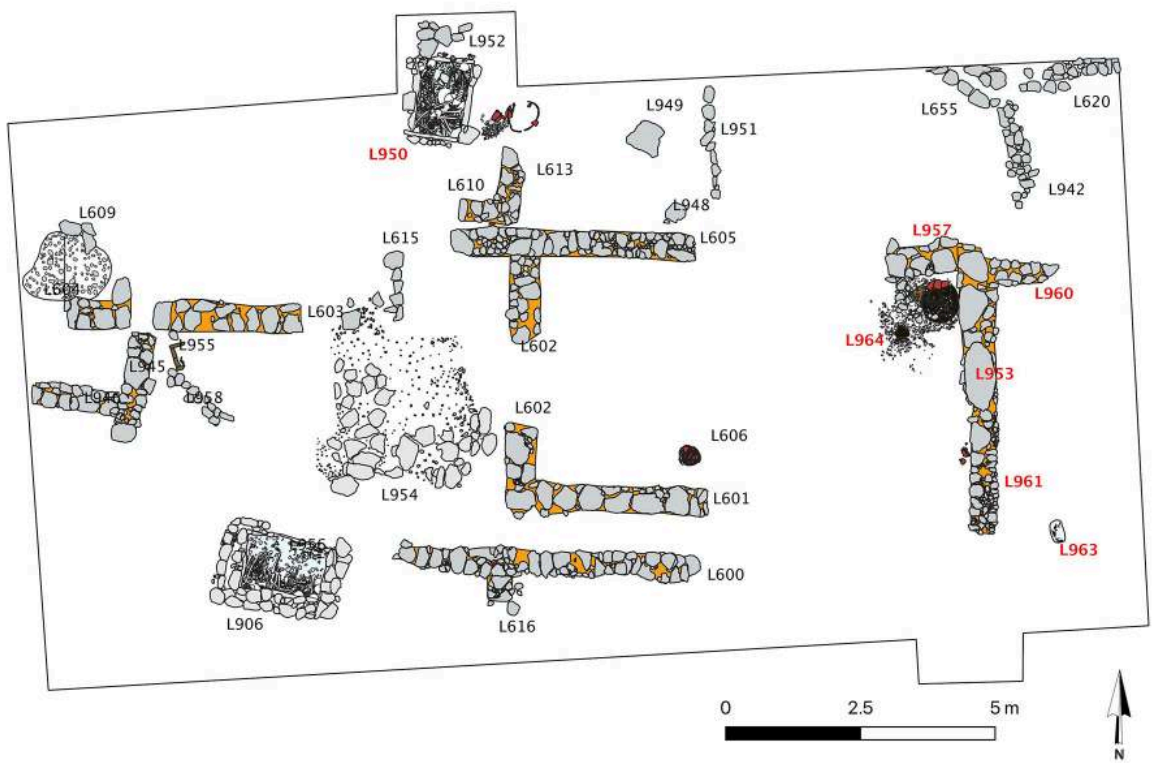

En gras et en rouge, les ensembles fouillés en 2019

R. Orgeolet, EFA/Mission Kirrha.

4 Le secteur 4 a fait l'objet de deux opérations distinctes: d'une part, la fouille de la grande ciste protomycénienne L950 découverte l'an passé, et d'autre part une exploration limitée des niveaux d'habitat HR I à l'Est du secteur.

\section{La tombe L950}

Camille Bouffiès 
Fig. 2. Plan de la tombe $L 950$ et succession des dépôts.

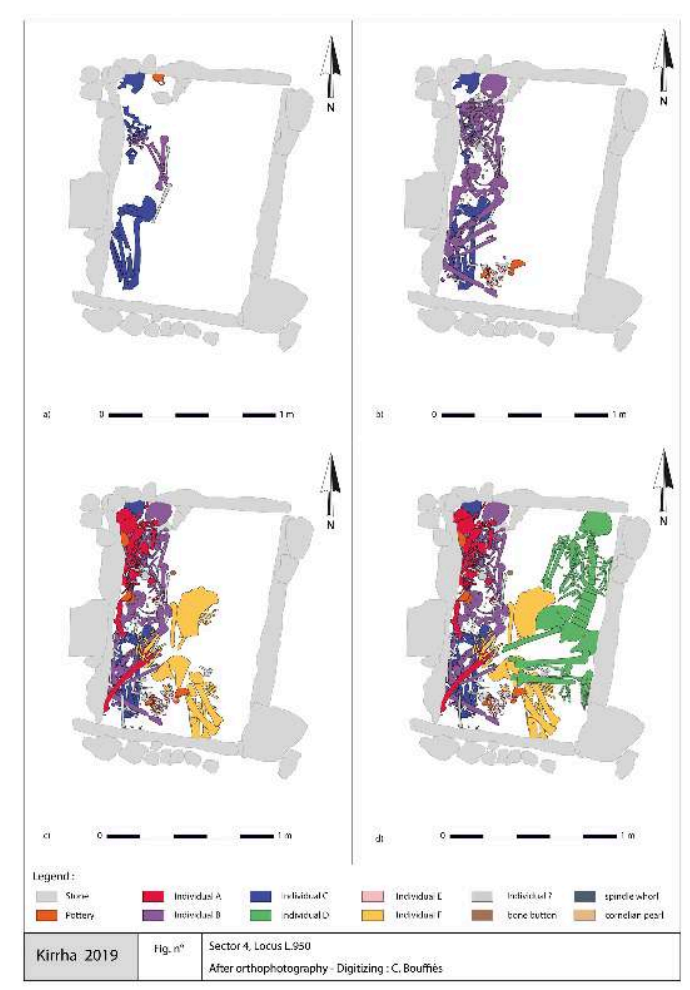

5 La sépulture L950 est une tombe à ciste mise au jour lors de la campagne 2018, lors de la fouille de l'espace 4.1.1, en limite nord de l'emprise du secteur 4 (fig. 1). Seules les dalles de couverture avaient été dégagées en 2018, la fouille de la structure étant l'un des objectifs de la campagne 2019.

6 Il s'agit d'une tombe à ciste dont le coffrage est constitué de quatre dalles en calcaire posées de chant, qui délimitent un espace intérieur rectangulaire de $1,38 \mathrm{~m}$ sur 0,92 m, d'environ $0,70 \mathrm{~m}$ de profondeur, orienté Nord-Sud (fig. 2). La ciste était scellée par trois grandes dalles de calcaire posées sur plusieurs petits blocs de calage destinés à égaliser la partie supérieure des dalles latérales. Les parois de la chambre étaient recouvertes par un enduit de ton rosé s'étant détaché par plaques qui se retrouvent dans le comblement de la sépulture. De l'enduit encore en place a toutefois été retrouvé à la base de la dalle latérale Sud. Le fond de la tombe a été aménagé par un lit de cailloux blancs (fig. 3). Des traces brunes correspondant probablement à de la matière organique ont été retrouvées sur ce lit de cailloux dans toute la partie Ouest de la tombe. Elles recouvrent également le coxal et le fémur gauche de l'individu C, le premier à avoir été déposé au sein de la tombe. Il pourrait s'agir d'une couche de matériau périssable, tel qu'un plancher en bois, servant à séparer deux phases de dépôt. Le comblement intérieur de la sépulture provient de l'infiltration du sédiment entre les dalles de couverture. Il s'agit d'un sédiment limono-argileux brun-gris très meuble qui ne recouvre pas complètement les ossements, dont une partie est apparue directement à l'air libre contre la paroi ouest dès l'ouverture de la tombe. 
Fig. 3. La tombe L950 et son lit de galets.

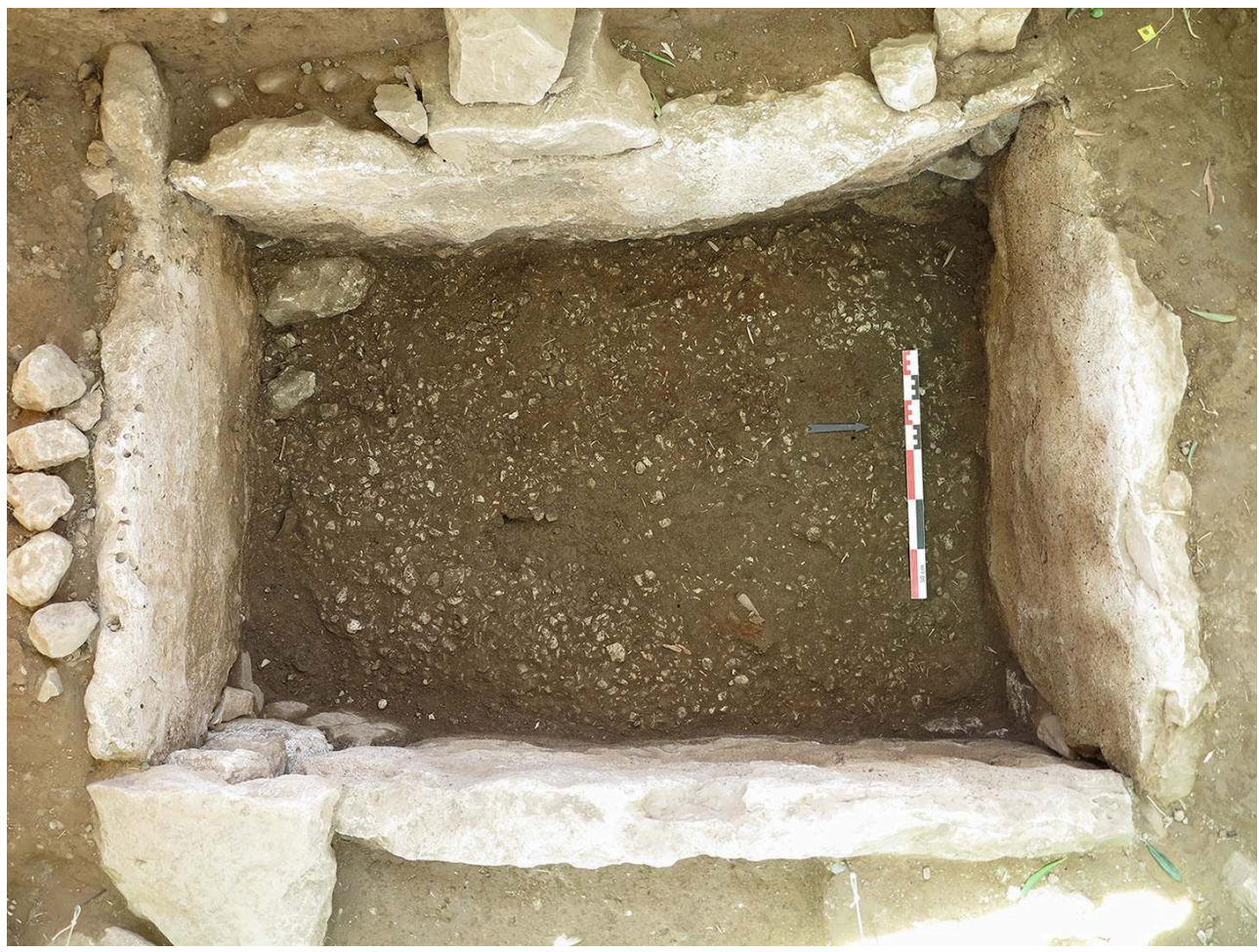

C. Bouffiès, EFA/Mission Kirrha.

7 Un sondage a été effectué à l'est de L950 (L: 1,25 m; 1: 0,5 m, h.: 0,45 m) afin de documenter le creusement de la sépulture, et de préciser les relations stratigraphiques de la sépulture avec les éléments de l'espace 4.1.1. L'implantation de la sépulture L950 succède à une phase d'utilisation domestique de l'espace 4.1.1, très peu de temps après son abandon au cours de l'HR I. Cette phase d'occupation, encore très peu documentée, est probablement à rapprocher de la phase F identifiée en 2018 au sein du secteur 4 et dont le mobilier céramique est caractéristique de l'HR I (voir rapport 2018). Le mobilier présent au sein de la sépulture constitue un ensemble homogène daté de l'HR I, tout comme le matériel retrouvé au sein de la sépulture L906. Les deux sépultures sont donc contemporaines et peuvent être attribuées à la phase D. L'utilisation de L950 s'est poursuivie tout au long de l'HR I, avant d'être condamnée par un remblai de nivellement précédant l'implantation de nouveaux espaces d'habitat lors de la phase C, datée de l'HM IIIB à l'HR IIIA.

8 La tombe L950 a reçu les dépôts successifs de six individus, dont cinq adultes (A, B, C, D et $\mathrm{F}$ ) et un périnatal (E) (fig. 2). Le premier individu inhumé au sein de la sépulture est le sujet C, qui se trouve en position primaire le long de la paroi ouest, orienté Nord-Sud. Il est allongé sur le dos, les membres inférieurs hyperfléchis. Le maintien du pied droit en connexion indique que l'individu est en position primaire, bien que de nombreux mouvements hors de l'espace initial du corps aient été provoqués par la décomposition en espace vide. Le crâne, la partie droite du thorax et le membre supérieur droit ont été perturbés par le dépôt d'un second individu dont il ne reste que le membre supérieur droit en position primaire, en avant du thorax du sujet C. Il est attribué au sujet B, un individu adulte de sexe indéterminé dont le reste du squelette a été déplacé pour être placé sur le sujet $C$, le long de la paroi ouest. Il est orienté Nord-Sud, allongé sur le dos, 
les membres inférieurs repliés avec les genoux relevés. Le déplacement du sujet B s'est probablement fait en cours de décomposition. En effet, une partie du squelette conserve des connexions lâches (thorax et ceinture scapulaire, bassin et fémurs), mais les os des mains et des pieds, qui correspondent à des connexions labiles, sont disséminés au sein de la sépulture. On observe également que les vertèbres cervicales sont déconnectées du reste du rachis, tout en conservant les connexions entre elles. L'individu A se trouve en position secondaire sur l'individu B contre la paroi ouest. Il s'agit d'un individu adulte, de sexe masculin. On remarque qu'une certaine logique anatomique a été restituée, bien que les connexions ne soient pas conservées. En effet, le crâne, les côtes gauches, le coxal droit et le fémur droit ont été placés dans l'ordre anatomique le long de la paroi ouest, orienté Nord-Sud. Le reste du squelette a été déposé sans aucune logique sur ces éléments. Les sujets $B$ et $A$ ont certainement fait l'objet de réductions afin de faire de la place pour les dépôts des individus $\mathrm{F}$ e D (fig. 2d). L'individu F est un adulte de sexe indéterminé. Il a été inhumé en position repliée sur le côté gauche au centre de la sépulture, dans sa partie Sud. Cet individu est très mal conservé et les différentes parties de son squelette ont été associées car elles gardent une logique anatomique, bien que les connexions ne soient pas observables (crâne, membre supérieur gauche, thorax et membre supérieur droit, bassin et membres inférieurs). Certaines connexions labiles sont conservées, telles que la main gauche et les pieds, ce qui indique qu'il est en position primaire. Il est recouvert par l'individu D, sans qu'il soit perturbé par celui-ci. Le dépôt du sujet $\mathrm{D}$ a donc eu lieu rapidement après celui du sujet $\mathrm{F}$. L'individu $\mathrm{D}$ est un adulte de sexe indéterminé. Il est allongé sur le dos, les membres inférieurs repliés sur le côté droit contre la paroi est, orienté Nord-Sud. Il s'agit d'un dépôt primaire car l'ensemble des déplacements peut être attribué à une décomposition en espace vide, et le pied gauche est parfaitement en connexion bien qu'il s'agisse de connexions labiles. 
Fig. 4. Vue depuis le sud de la réduction du sujet périnatal (E).

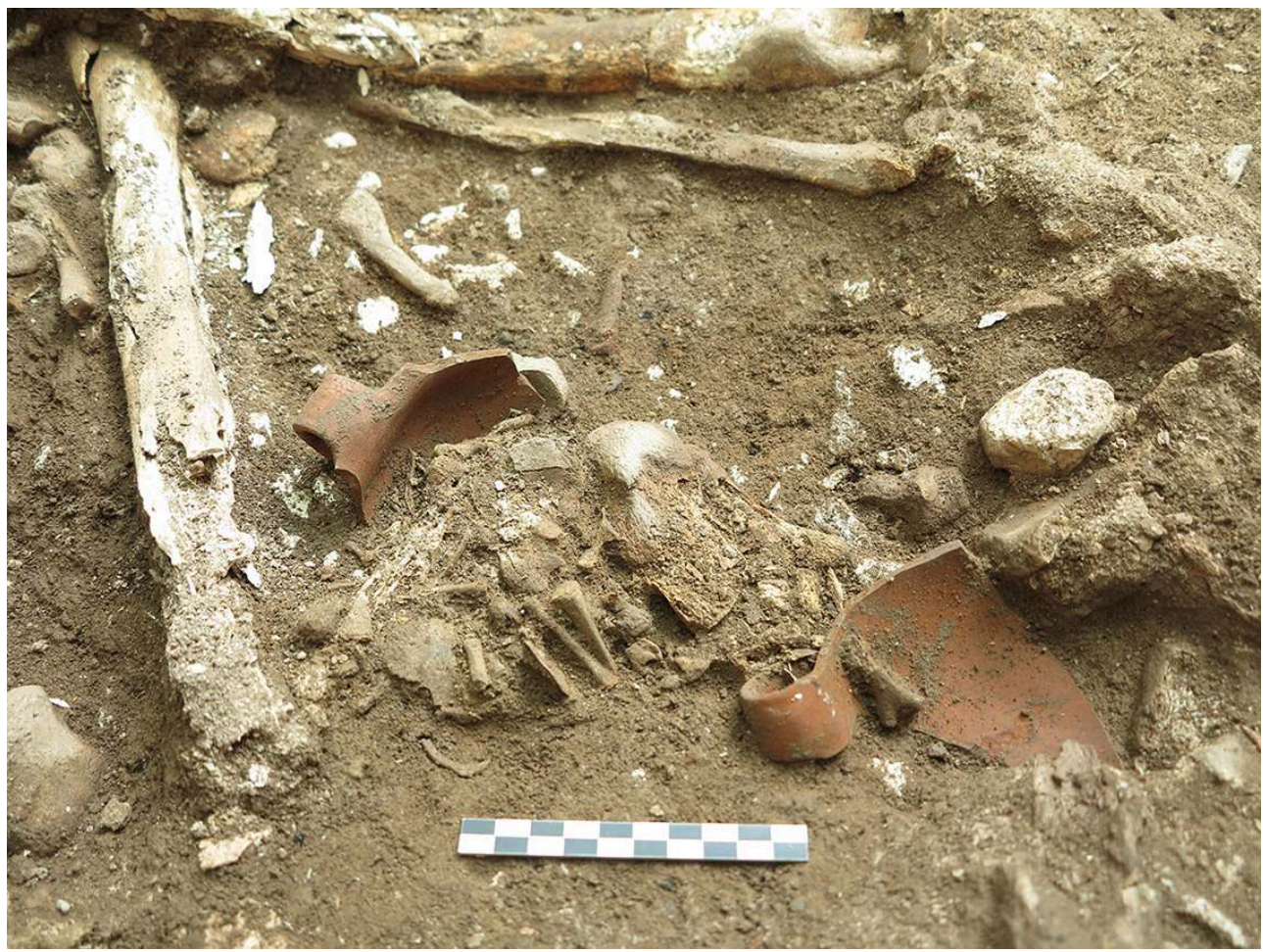

C. Bouffiès, EFA/Mission Kirrha

Enfin, un dépôt secondaire constitué des restes d'un individu périnatal regroupés entre deux fragments d'un bol en céramique est présent entre les membres inférieurs du sujet B et le sujet $\mathrm{F}$ (fig. 4). La décomposition du corps a probablement eu lieu sur place car le dépôt présente une très bonne représentation osseuse, même des éléments les plus petits tels que les germes dentaires, les phalanges et les vertèbres. Ce n'est qu'après la décomposition du corps que les ossements auraient été rassemblés. Cette opération a eu lieu après le déplacement de l'individu $B$ car il recouvre des os des pieds déconnectés appartenant soit à $\mathrm{B}$ soit à $\mathrm{A}$. Il a ensuite été perturbé par le dépôt du sujet $\mathrm{F}$.

10 La sépulture L950 a donc accueilli des pratiques funéraires complexes impliquant le dépôt successif de plusieurs individus, aussi bien adultes qu'immatures, à des intervalles plus ou moins rapprochés, et la réduction des sujets inhumés le plus anciennement. On observe que même chez les individus réduits, une attention particulière a été apportée au maintien d'une logique anatomique et à la conservation de l'orientation Nord-Sud. La représentation osseuse est très bonne, ce qui indique que l'ensemble des individus s'est décomposé à l'intérieur de la tombe et qu'il n'y a pas eu de prélèvement d'ossements. Pour les individus encore en position primaire, il semble que la position allongée sur le dos, ou sur le côté, avec les membres inférieurs repliés soit privilégiée. 
Fig. 5. Sélection du mobilier de la tombe L950.
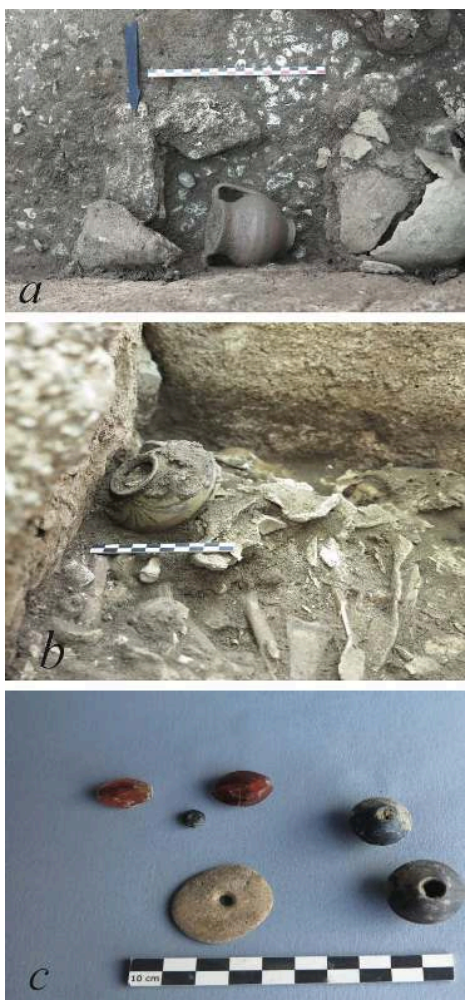

C. Bouffiès (5a \& 5b), L. Garnery (5c), EFA/Mission Kirrha.

11 Le mobilier funéraire comprend cinq vases en céramique qui constituent un ensemble cohérent daté de l'HR I, ainsi que plusieurs éléments de parure dont deux fusaïoles et une perle en stéatite, deux perles en cornaline, et une plaque en os perforée (fig. 5c). Un alabastre entier était déposé au sommet de l'assemblage osseux, directement à l'air libre (fig. 5b). Deux vases, l'un représenté par le pied et le fond, l'autre complet, ont été retrouvés mêlés aux ossements du sujet A. Ils ont probablement été déplacés avec les os de l'individu A lors de sa réduction. Deux fragments d'un même bol avec anses délimitaient le dépôt secondaire du sujet périnatal. Plusieurs fragments semblant appartenir au même vase ont été retrouvés, dispersés dans l'angle Sud-Ouest de la tombe. Ce bol aurait donc été déposé dans la tombe entier, puis aurait été fragmenté lors d'un nouveau dépôt, et les fragments réutilisés lors de la réduction du sujet périnatal. Enfin, un troisième vase entier se trouvait en position primaire au sein d'un espace délimité par trois petits blocs contre la paroi nord de la sépulture (fig. 5a). Cet aménagement date probablement de la première phase d'utilisation de la sépulture car les blocs et le vase reposaient directement sur le niveau de cailloux blancs au fond de la tombe. Concernant les éléments de parure, une première fusaïole a été retrouvée sur le fémur droit du sujet B, probablement en position secondaire. Une perle en cornaline se trouvait en position primaire contre le radius gauche du sujet $\mathrm{F}$ au niveau du poignet. Elle a pu faire partie d'un bracelet. Une seconde fusaïole a été mise au jour à environ $10 \mathrm{~cm}$ à l'ouest et ne semble pas être en position primaire. Une rondelle en os perforée a été retrouvée à $5 \mathrm{~cm}$ environ de la tête fémorale droite du membre supérieur en position primaire de l'individu B. Encore une fois, il est impossible de savoir si elle est en position primaire ou non, et donc de l'associer à un individu en particulier. Enfin, 
une deuxième perle en cornaline et une petite perle en stéatite ont été retrouvées au tamisage.

\section{L'habitat du secteur 4, phases anciennes}

Rodolphe Martinez, Adèle Vorsanger

La campagne 2019 avait pour objectif premier, sur le secteur 4, l'exploration de la phase F. Cette phase d'occupation, la plus ancienne mise en évidence sur le secteur, avait été identifiée lors de la campagne de fouilles de 2018 et attribuée à l'HR I. En 2018, elle était illustrée par les murs perpendiculaires L953 et L957, associés à un niveau de sol fouillé, par la force des choses, sur une surface assez restreinte, ainsi que par un aménagement en brique crue identifié sous la sépulture L906 (fig. 4). En 2019, nous avons tâché d'explorer de façon plus large les niveaux de la phase F. La fouille s'est concentrée aux environs immédiats des murs L953 et L957. Il s'est avéré que ces murs s'articulent à un état architectural antérieur. À ces deux états du bâti correspondent à deux occupations distinctes, que l'on désignera provisoirement par $\mathrm{F}(1)$ et $\mathrm{F}(2)$.

\section{La phase $F(1)$}

\section{L'architecture}

Fig. 6. Secteur 4 : l'architecture de la phase F explorée en 2019.

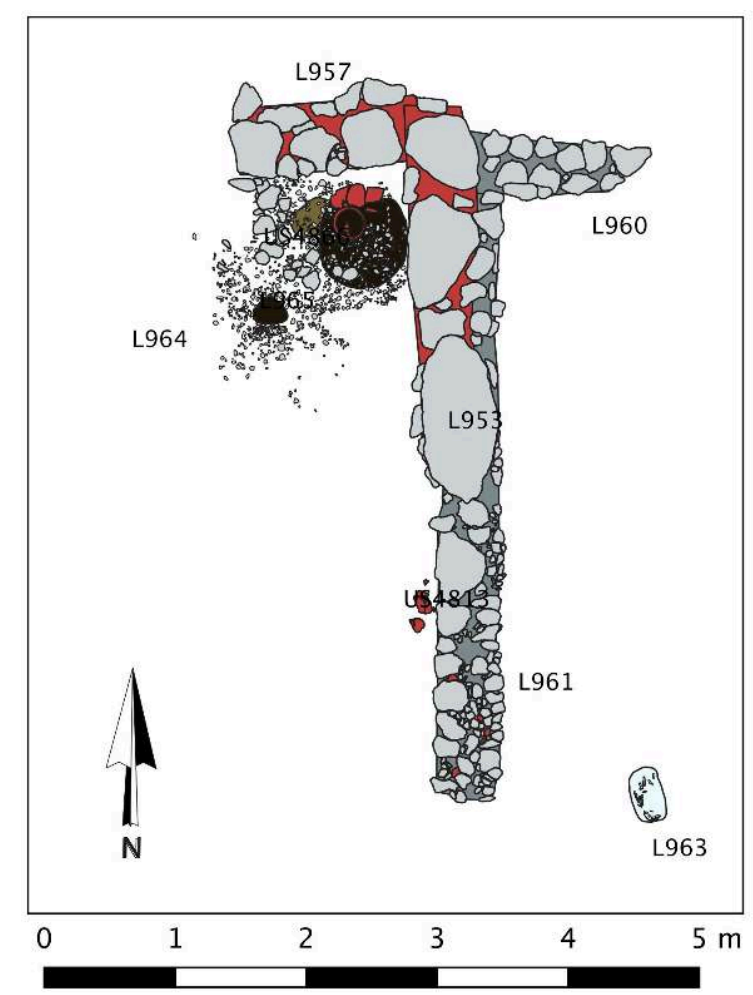

En vert, la phase $F(1)$; en orange, la phase $F(2)$.

R. Orgeolet, EFA/Mission Kirrha.

En 2018, les murs perpendiculaires L953 et L957 de la phase F(2) avaient été mis au jour, mais leur base n'était pas apparente (fig. 6). La recherche de la base des murs a montré 
que L953 repose, sans fondations, à une altitude légèrement plus élevée que L957 ; ce dernier, en revanche, s'appuie sur une maçonnerie antérieure, appartenant à la phase $\mathrm{F}(1)$ : le mur L961. Les appareils des deux murs, qui suivent une orientation NordSud, sont nettement distincts. Alors que L957 est constitué de blocs de très gros module, L961 est un mur à deux rangées de moellons de petit à moyen module. On repère par endroits dans la maçonnerie des traces de mortier. L961 n'est pas recouvert sur toute sa longueur par L957, mais se poursuit sur un peu plus de deux mètres vers le Sud. L961 forme un angle vers l'Est avec le mur L960, orienté Est-Ouest, et possédant un appareil similaire à L961. Malheureusement, L960 n'a, pour l'heure, pas pu être mis au jour dans toute sa largeur à cause de la présence d'un olivier, ni dans toute sa longueur car il se poursuit dans une berme d'environ un mètre de hauteur. Les murs perpendiculaires L960 et L961 semblent donc constituer les limites Nord et Ouest d'un espace aujourd'hui largement occupé par un olivier. Pour autant, des niveaux d'occupation peuvent être associés à ces murs.

\section{Les niveaux d'occupation}

Différents niveaux de sol constituent une phase d'occupation qu'il faut probablement associer aux murs L960 et L961.

\section{Un niveau de sol en terre battue : US4852}

15 À l'ouest de L961, au ras des pierres de la première assise de ce mur, un horizon d'occupation complexe a été dégagé. L'US4852 est un niveau de sol argileux en terre battue, marqué par des traces importantes de rubéfaction. On y distingue des inclusions de charbons. Trois huîtres, posées à plat sur le niveau et alignées sur un axe est-ouest, ont été laissées en place.

\section{Un vase de stockage in situ : L964}

Le sol (US4852) est délimité au Nord par l'emprise d'un cailloutis de galets, l'US4845, dans lequel s'ouvre l'embouchure d'un vase de stockage fiché dans le sol (fig. 7). Un trou de poteau peu profond (L965), au fond tapissé d'une mince couche de mortier y est également pratiqué. Un petit cratère gisait, brisé, sur le cailloutis et au contact de l'embouchure du grand vase. Deux tessons de ce cratère ont été retrouvés dans le remblai qui remplissait le vase de stockage. 
Fig. 7. Le vase L964.

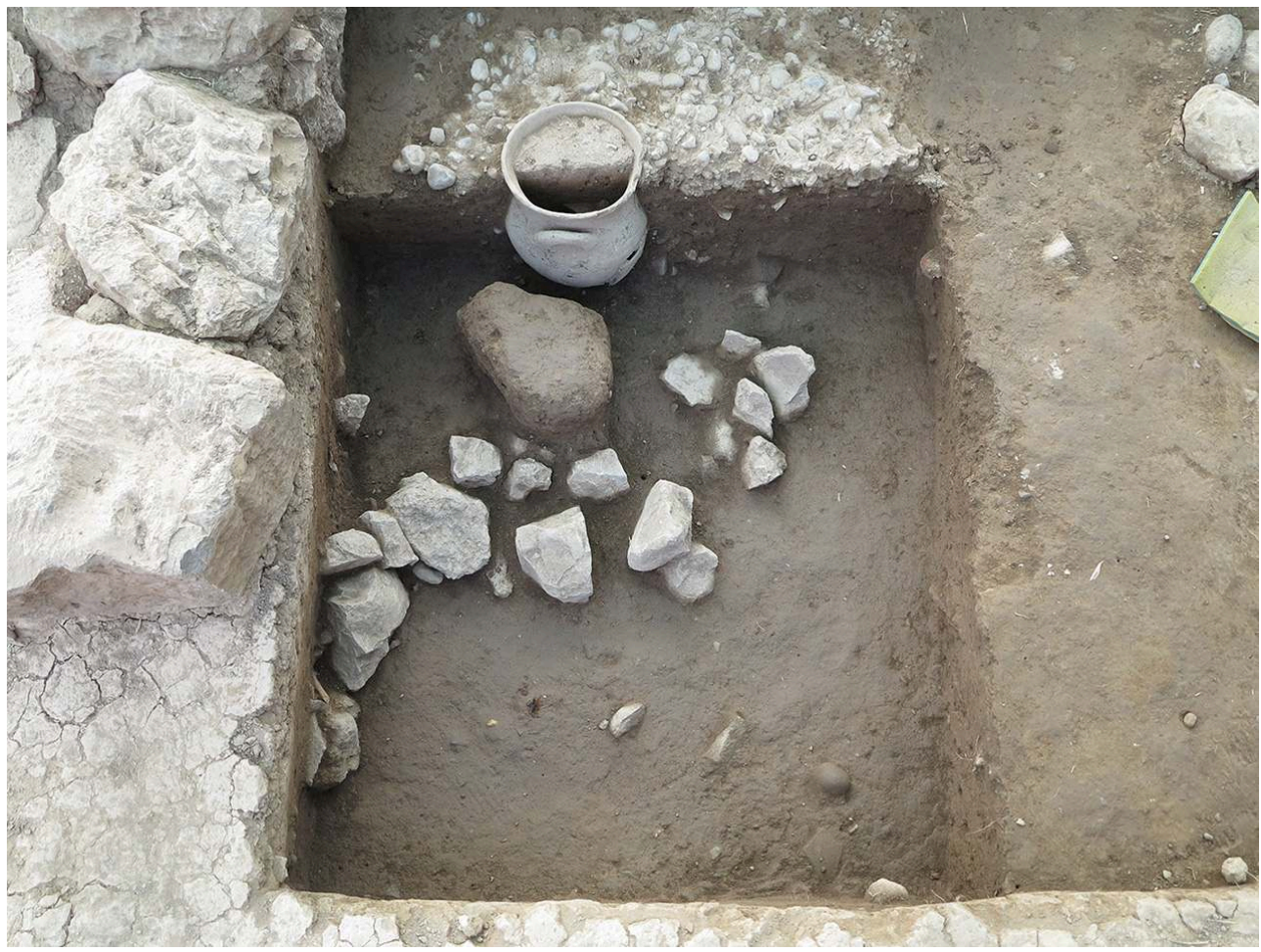

A. Vorsanger, EFA/Mission Kirrha

Fenêtres sur deux autres niveaux de sols : US4850 et US4857

Deux autres niveaux de sol semblent pouvoir être mis en relation avec surfaces précédemment décrites. Ces quatre niveaux de sol (US4852, U4845, US4850 et US4857), présentent des éléments de ressemblance : indices de rubéfaction ou de carbonisation, présence de mortier. De plus, toutes quatre reposent à des cotes d'altimétrie proches, autour de $6,30 \mathrm{~m}$ asl, d'aplomb avec le niveau d'implantation des murs L960 et L961. Ces éléments invitent à voir dans cet ensemble de niveaux un unique horizon d'occupation, correspondant à l'état architectural représenté par les murs L960 et L961.

\section{Remblais et démolition}

L'abandon de la phase d'occupation $\mathrm{F}(1)$ est caractérisé, d'une façon générale sauf à la surface de l'US4845, par des traces de rubéfaction et de carbonisation. Le vase de stockage se remplit progressivement, semble-t-il, de terre de remblai. On y distingue en effet deux niveaux de remplissage successifs. On trouve dans la partie inférieure du remplissage supérieur deux tessons du petit cratère brisé à la surface du cailloutis US4845.

\section{La Phase F2}

\section{L'architecture}

Dans un second temps et après un premier abandon, le mur L961 est réemployé comme base d'un nouveau mur, le mur L957 (fig. 6). Déjà observé en 2018, L957 est d'orientation Nord-Sud et mesure 3.10 de longueur pour $0.60 \mathrm{~m}$ de large. Il présente 
une construction de blocs de très gros module $(90 \times 50 \times 20 \mathrm{~cm})$, disposés en panneresse couchée et matérialisant toute la largeur de la maçonnerie.

L957 s'inscrit par ailleurs perpendiculairement à L953, lui aussi mis au jour lors de la campagne de 2018. L953 est orienté selon un axe Ouest-Est et mesure $1,35 \mathrm{~m}$ de longueur pour 0,64 $\mathrm{m}$ de large au maximum. Il présente une mise en œuvre fruste de blocs de calcaire de module moyen $(50 \times 20 \times 20 \mathrm{~cm})$, disposés de manière à définir toute la largeur de la maçonnerie et associés à de petites pierres de calage. L'ensemble est lié par une matrice limoneuse brune meuble et homogène.

\section{Les niveaux d'occupation}

Le niveau de sol US 4813 a été identifié sur une large zone comprise dans la fenêtre de fouille. Il s'étend à l'ouest et au sud de l'angle formé par les murs L953 et L957, auxquels il semble rattaché. Ses limites sont pour le moment artificielles et le sondage est bloqué à l'Ouest par un olivier qui réduit considérablement la fenêtre de fouille.

Il s'agit d'une couche très compacte au sédiment argileux, de couleur brun-sombre. L'US 4813 comporte de multiples inclusions de particules charbonneuses et a livré de nombreux tessons de céramique et plusieurs éléments lithiques, souvent taillés, en obsidienne ou en silex. On notera particulièrement un fond de vase accompagné de plusieurs tessons du même objet, retrouvé au Sud-Est de la fenêtre de fouille, dans le prolongement de L957 vers le Sud.

Un second niveau de sol longe le parement est de L957, dans ce qui pourrait être interprété comme l'extérieur de l'espace défini par les deux murs L953-L957. Celui-ci a pu être observé dans une zone restreinte par l'olivier au nord-est et par la limite orientale du sondage.

Installée par-dessus des remblais, l'US 4819 est postérieure à la séquence formée par les murs L960 et L961. Ce sol est caractérisé par un sédiment limono-argileux brun sombre, meuble et plutôt homogène. Il contient une quantité importante de matériel céramique et lithique posé à plat et plusieurs moellons en surface. Toutefois, la couche présente d'importantes différences de niveaux. Il pourrait s'agir d'un ensemble niveaux différents superposés, résultant de recharges successives en terre battue.

\section{La tombe L963}

Camille Bouffiès

La tombe L963 est une inhumation primaire individuelle d'un sujet immature appartenant à la classe d'âge des [0-4] ans (fig. 8). Elle a été découverte en limite est du secteur 4. Le creusement n'est pas visible, le comblement de la sépulture n'étant pas différenciable de l'encaissant, un sédiment argilo-limoneux brun-jaune compact correspondant à un niveau de remblai de briques fondues. Le squelette apparait à une altitude de 6,66 m asl (crâne). 
Fig. 8. La sépulture L963.

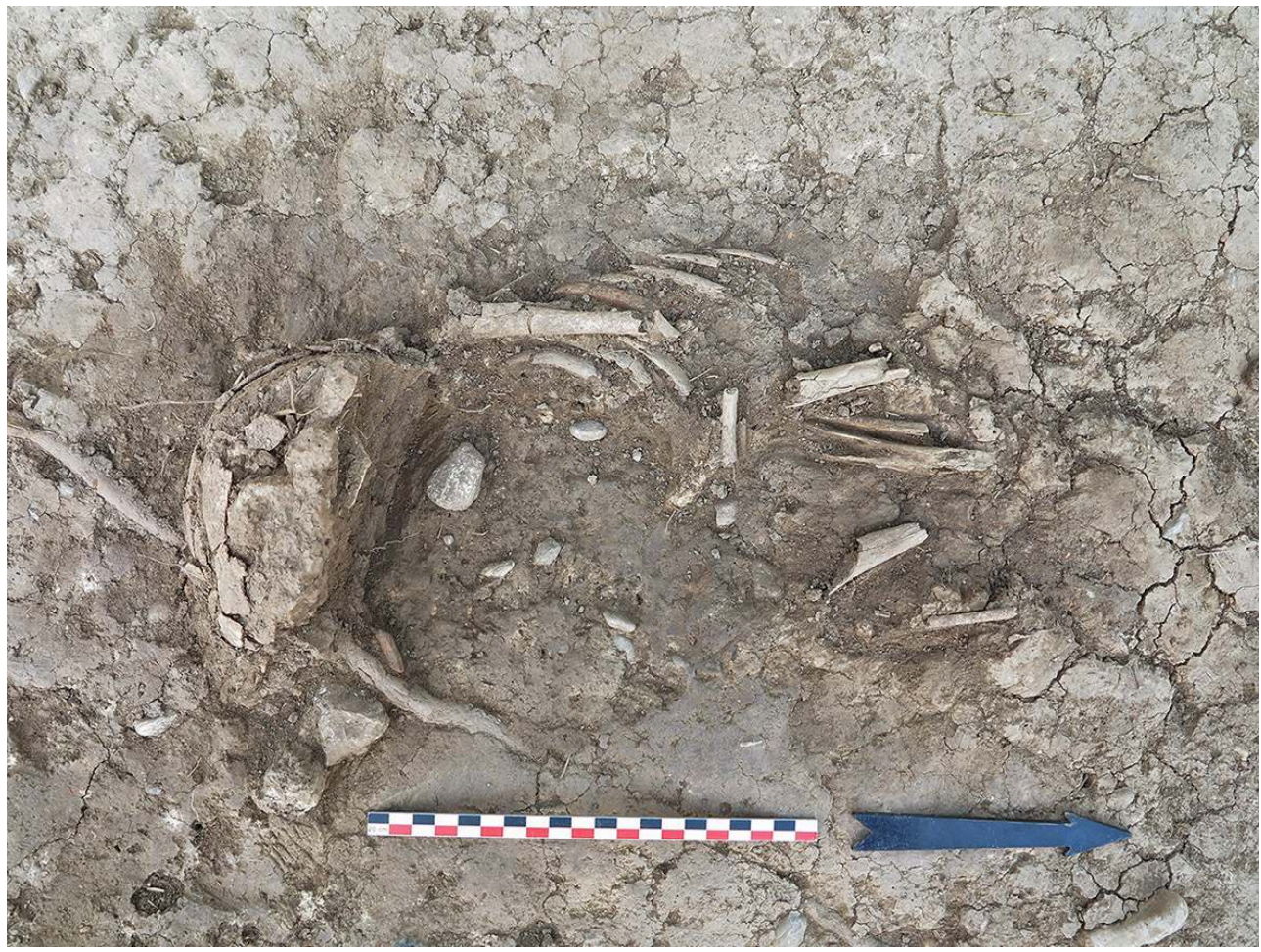

J. Sicard, EFA/Mission Kirrha.

Les ossements sont mal conservés. Les éléments encore présents sont le crâne, les côtes gauches, la scapula gauche, le membre supérieur gauche et les membres inférieurs. La partie droite du sujet a peut-être été recoupée par une structure indéterminée. Les épiphyses ne sont pas conservées. Le sujet est allongé sur le dos, orienté Sud-Nord, le membre supérieur gauche replié à $90^{\circ}$ en avant du thorax et les membres inférieurs probablement en extension. On observe que le tibia et la fibula gauches sont remontés le long du fémur gauche, ce qui indique une décomposition en espace vide et donc la présence d'un contenant en matière périssable qui a disparu.

\section{Le secteur 2-3-5}

† Simon Sedlbauer, Anne-Zahra Chemsseddoha, Marie De Jonghe, Maria Katsimicha \& Laetitia Laquay

\section{Préambule}

Dans un souci de cohérence, il a été décidé, à l'issue de cette mission, de renommer les différentes phases reconnues tout au long des campagnes passées. Les correspondances entre les anciennes dénominations et celles adoptées à présent, employées dans les lignes qui vont suivre, sont représentées dans le tableau ci-dessous (fig. 12). 


\begin{tabular}{|l|l|}
\hline vestiges contemporains : XX $\mathrm{e}$. & phase A \\
\hline vestiges peu lisibles postérieurs en stratigraphie relative à la phase C & phase B \\
\hline $\begin{array}{l}\text { phase A : vestiges de la nécropole de la période transitionnelle HM III - } \\
\text { HR I/II }\end{array}$ & phase C \\
\hline phase B : vestiges d'habitat de l'HM III & phase D \\
\hline phase C : vestiges d'habitat de l'HM II & phase E \\
\hline
\end{tabular}

Fig. 9. Tableau de correspondance des phases.

\section{Introduction}

Les objectifs de la campagne 2019 dans le secteur 2-3-5 (fig. 10) étaient dans la lignée de ceux énoncés en 2018 : d'une part, la poursuite de la réunion des zones 2-3 et du secteur 5 ; d'autre part, terminer de fouiller la nécropole de la période transitionnelle (phase C) sur l'ensemble du secteur investigué ; enfin, poursuivre et finaliser la fouille, notamment dans le secteur 5 au Sud-Est, de contextes d'habitat sous-jacents du Bronze moyen.

À l'issue de cette mission, les objectifs concernant le funéraire ont été pleinement atteints. Tous les contextes dont la fouille avait été initiée en 2018 ont été intégralement traités (L258, L261, L266, L274, L283, L504). En outre, les différents niveaux de fréquentation de la nécropole ont été minutieusement démontés ce qui a permis la mise au jour de nombreux contextes funéraires supplémentaires (L288, L290, L293, L295, L309, L314) dont la fouille a également pu être menée à terme.

31 Il s'avère donc qu'en l'état actuel des opérations de terrain, tous les niveaux de fréquentation et sépultures associées en lien avec la nécropole (phase $\mathrm{C}$ ) ont été entièrement documentés et purgés, à l'exception peut-être de L309 (cf. infra, rapports d'étude anthropologique).

Concernant les vestiges d'habitat sous-jacent du Bronze Moyen, les efforts se sont concentrés sur des contextes précis et cohérents dont la documentation exhaustive a été finalisée. Il s'agit notamment de l'édifice 5.1 et de ses niveaux de sols intérieurs et extérieurs associés, de la vaste construction sur soubassement en pierre s'apparentant à un enclos ou une plateforme formée par les murs L269, L270 et L313 et enfin d'un bâtiment lacunaire dont seul l'angle sud-ouest matérialisé par les murs L206 et L291 a été reconnu. 
Fig. 10. Plan général du secteur 2-3-5.

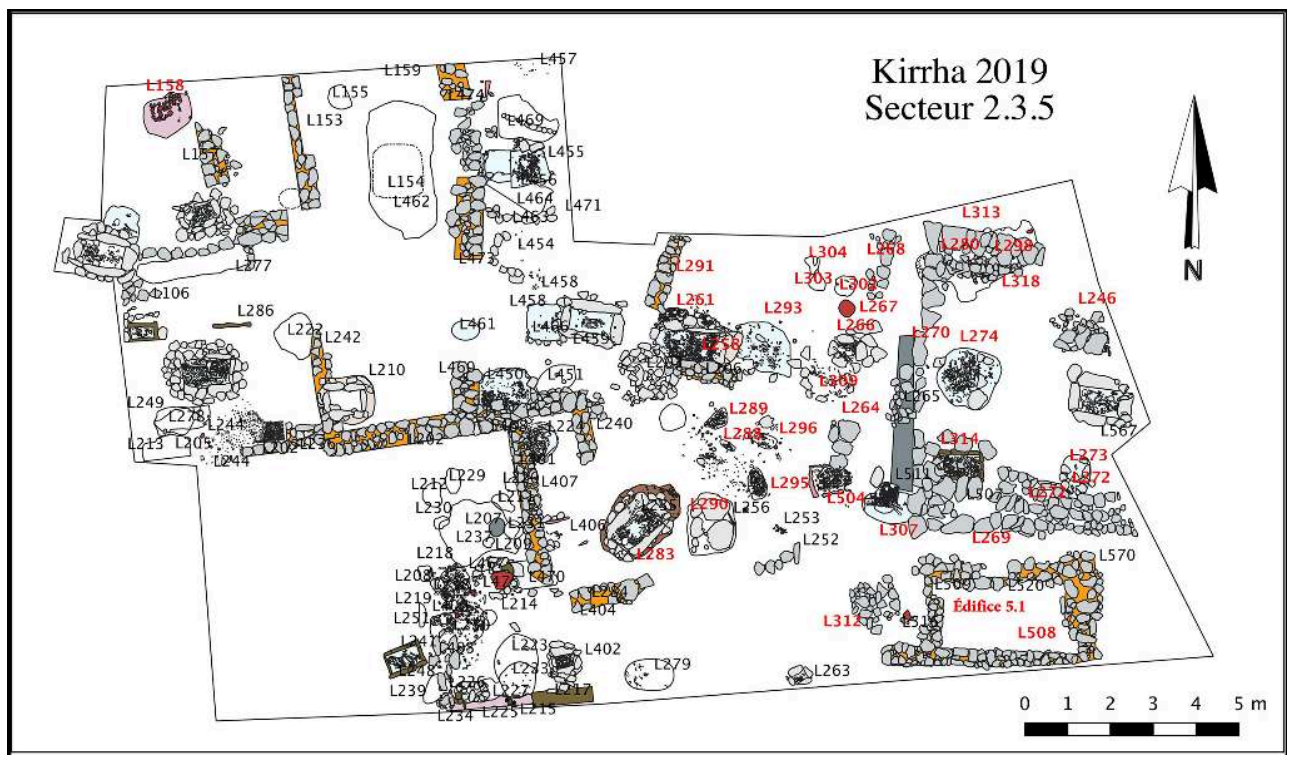

En gras en rouge, les ensembles fouillés en 2019).

R. Orgeolet, EFA/Mission Kirrha.

\section{Stratigraphie générale} L 504，L 288，L 290，L 293，L 295，L 309，L 314), nous renvoyons directement aux différentes études réalisées par les membres de l'équipe anthropologique présents durant toute la durée du chantier. Les contextes sont décrits du point de vue architectural et stratigraphique. Enfin, toutes les observations anthropologiques réalisées lors du démontage des ossements sont présentées de manière exhaustive (cf. infra, rapports d'étude anthropologique).

\section{Phase D et E : l'habitat du Bronze Moyen}

Le mur L206, dégagé en 2014 et 2018 appartient au vu de sa cote basse d'implantation à la phase E. La campagne de 2019 a permis de mettre au jour un mur (L291), orienté perpendiculairement suivant un axe Nord-Sud, qui semble pouvoir lui être associé 
(fig. 11). L'agencement de ces deux soubassements pourrait matérialiser l'angle SudOuest d'un édifice se prolongeant en dehors des limites de la fouille.

En lien avec cet espace bâti, plusieurs petites fosses charbonneuses, possiblement des vidanges de foyer, des surfaces rubéfiées (L302, L303 et L304) ainsi qu'un vase de stockage en place (L267) évoquent des activités domestiques à ses abords (fig. 12).

Fig. 11. Vue d'ensemble des murs L206, L291 et de la ciste L258, depuis le Sud-Ouest.

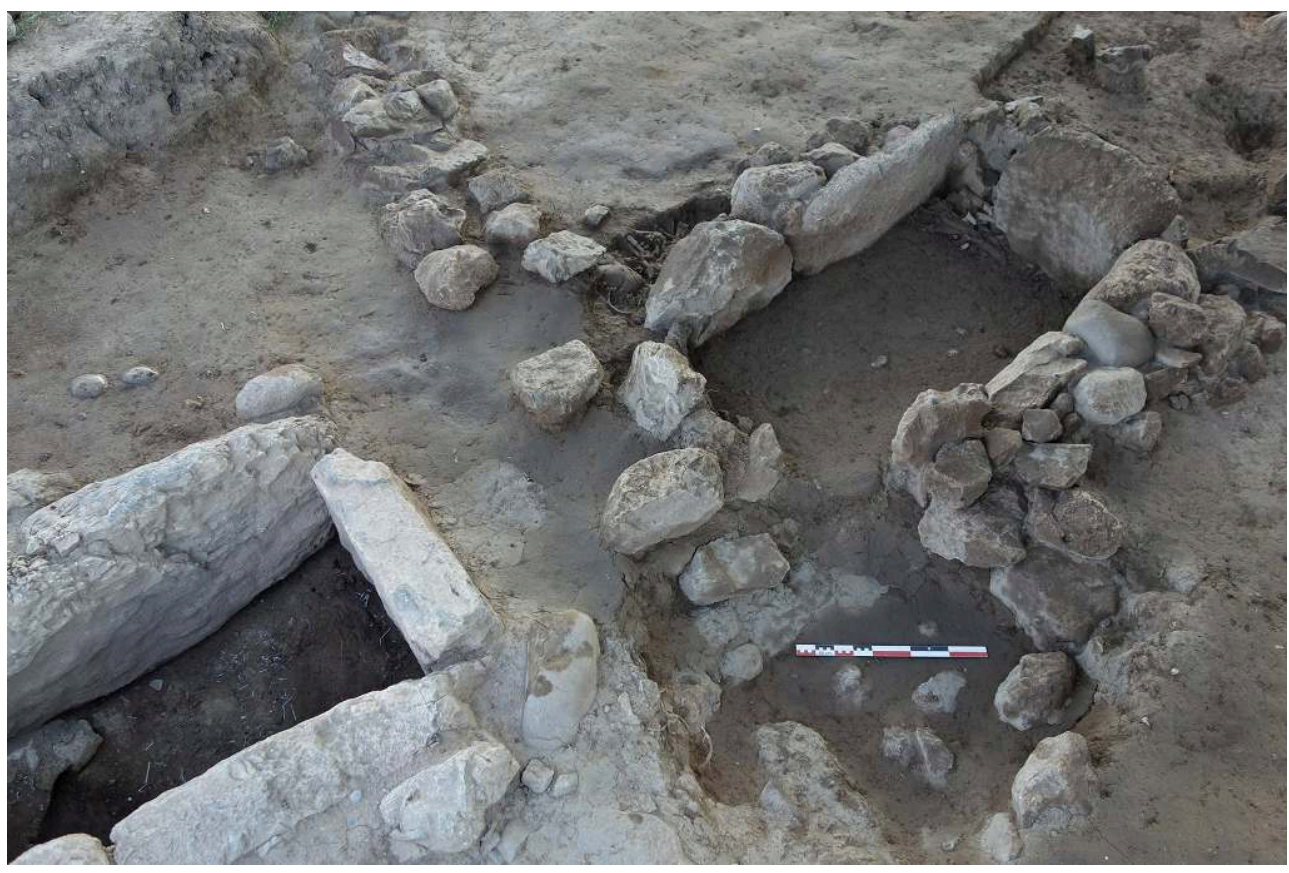

S. Sedlbauer, EFA/Mission Kirrha. 
Fig. 12. Vue d'ensemble des fosses charbonneuses et foyer L302, L303 et L304, depuis le NordOuest.

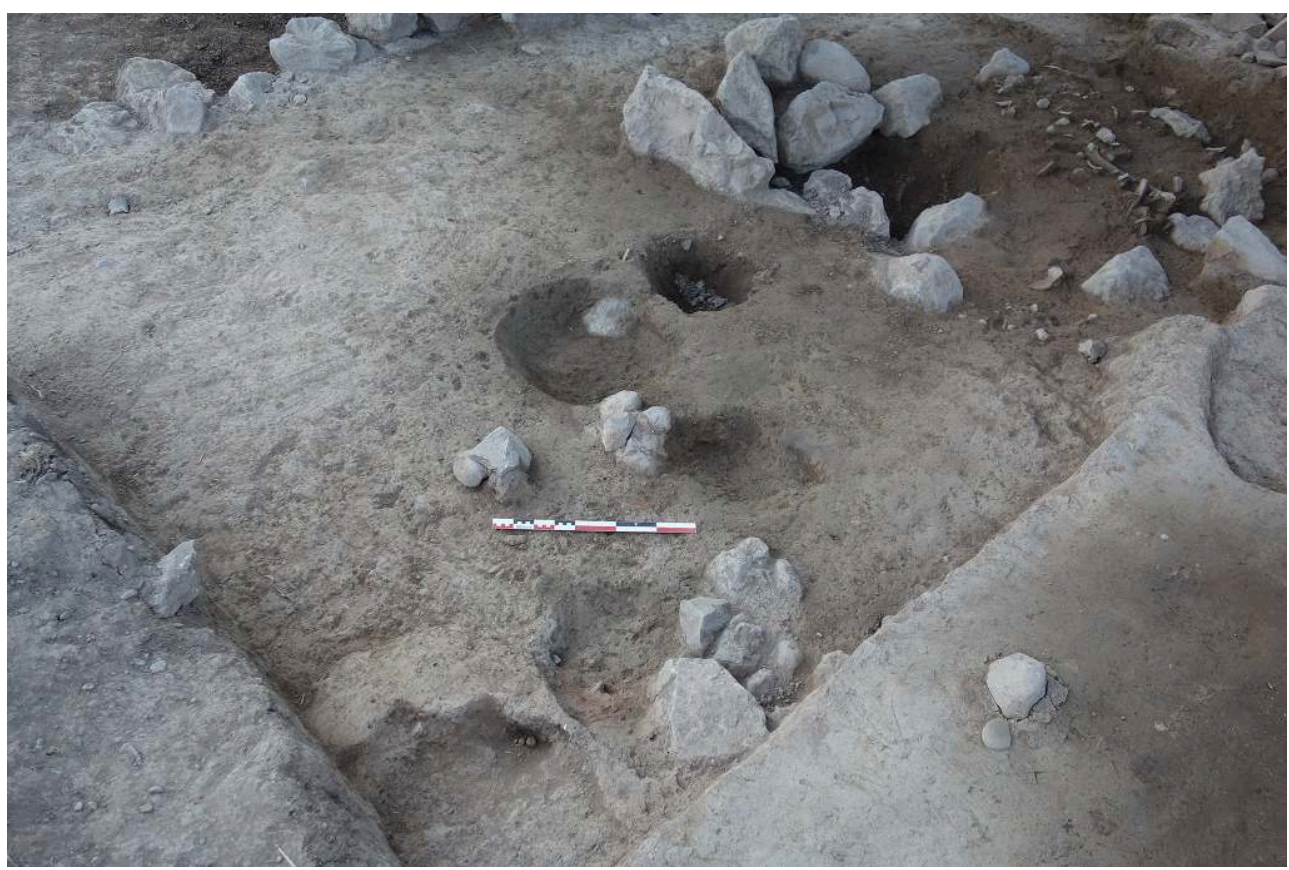

S. Sedlbauer, EFA/Mission Kirrha.

La fouille de l'édifice 5.1 a été poursuivie et finalisée, ce qui a permis de mieux appréhender son évolution architecturale (fig. 10). L'état le plus récent est matérialisé par les murs L508, L520 et L570. Un seuil de $0,7 \mathrm{~m}$ de longueur matérialise un accès à travers le mur L508 ce qui suggère que l'édifice se poursuit en direction du Sud sous la berme. Ces murs reprennent en partie le tracé de soubassements antérieurs dont seules des portions ont été observées dans l'angle Nord-Ouest (L316, L317) ainsi que dans l'angle Nord-Est (L287). Enfin, trois blocs disposés de chant(L315) semblent être rapportés ultérieurement en façade de l'édifice au Nord. La poursuite de la fouille de cet espace a permis de caractériser le niveau d'occupation en lien avec l'état le plus ancien du bâti. Il s'agit d'une couche (US $6169=$ US 6150) brunâtre à noirâtre parsemée de résidus charbonneux sur laquelle ont été découverts deux fragments de meules reposant à plat. En outre, deux petites fosses (L292 et L299) dont les parois sont enduites de chaux ont été identifiées en surface de ce sol dans l'angle Nord-Est de la pièce (fig. 13). Ces dernières pourraient éventuellement correspondre au négatif laissé par des vases de stockage ou encore par des contenant en matériaux périssable de type vannerie. 
Fig. 13. Vue d'ensemble du sol US6169=US6150, des meules à plat et du négatif $L 292$, depuis le Sud-Est.

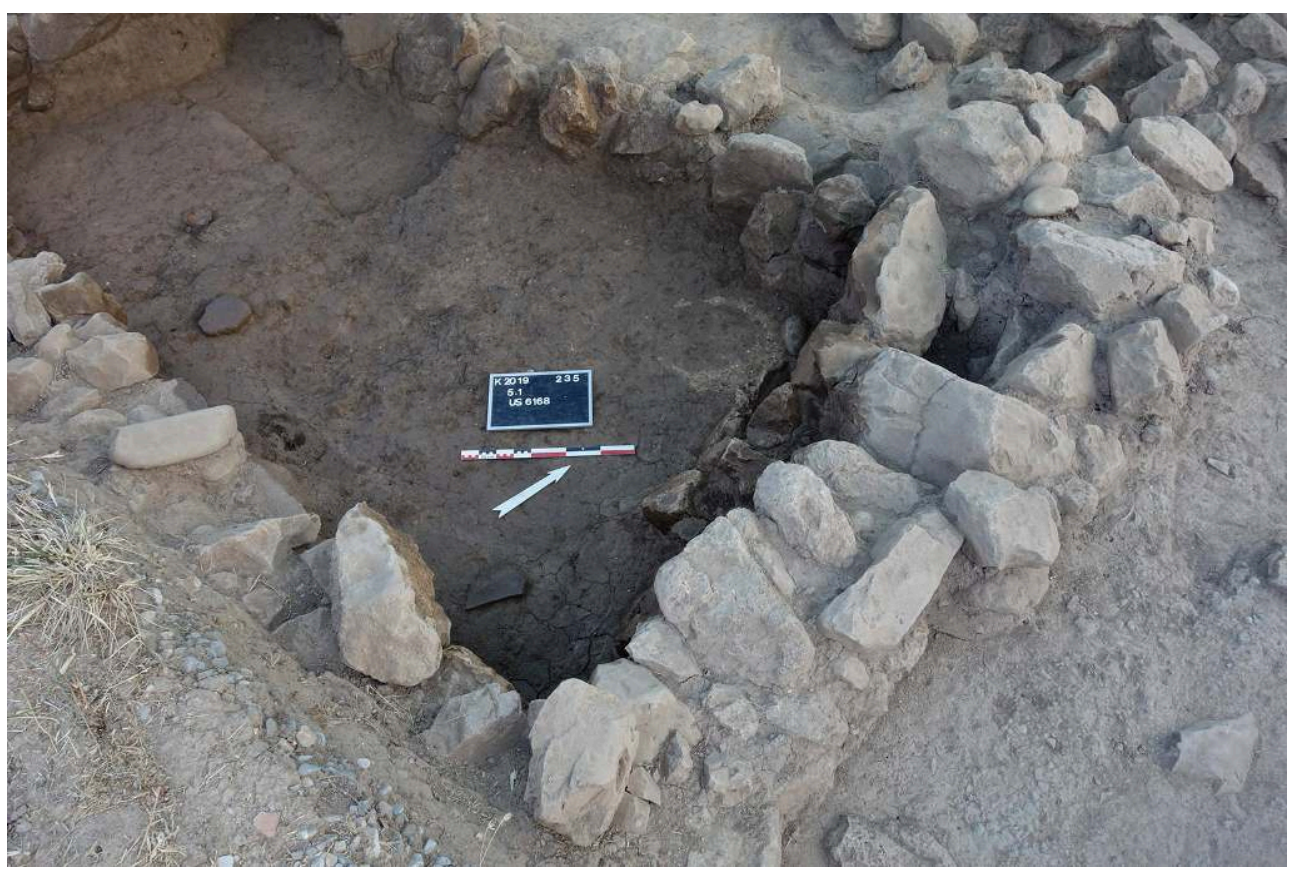

S. Sedlbauer, EFA/Mission Kirrha.

Les sols extérieurs en phase avec ce bâtiment ont également été intégralement fouillés à l'issue de la mission. La couche US 6085, identifiée contre le pignon Est de l'édifice 5.1, rend compte d'une surface de piétinement constituée de céramique, de faune et de galets formant une fine couche d'1 à $2 \mathrm{~cm}$ d'épaisseur. Plus au Nord et à l'Ouest, le sol US 6090, composé d'un sédiment limono-argileux homogène, est jonché de concentrations de matériaux analogues à celles observées dans l'horizon de circulation US 6085. La couche sous-jacente (US 6242), possiblement en lien avec l'état le plus ancien de l'édifice 5.1, accueille deux fosses dépotoirs (L305 et L308), une importante vidange de foyer exclusivement constituée de cendres et de particules charbonneuses (L306) et enfin une fosse (L307) au fond de laquelle a été découvert une inhumation primaire (fig. 14) scellée par un comblement très organique et détritique. 
Fig. 14. Vue de la fosse L307 accueillant une inhumation primaire, depuis le Sud.

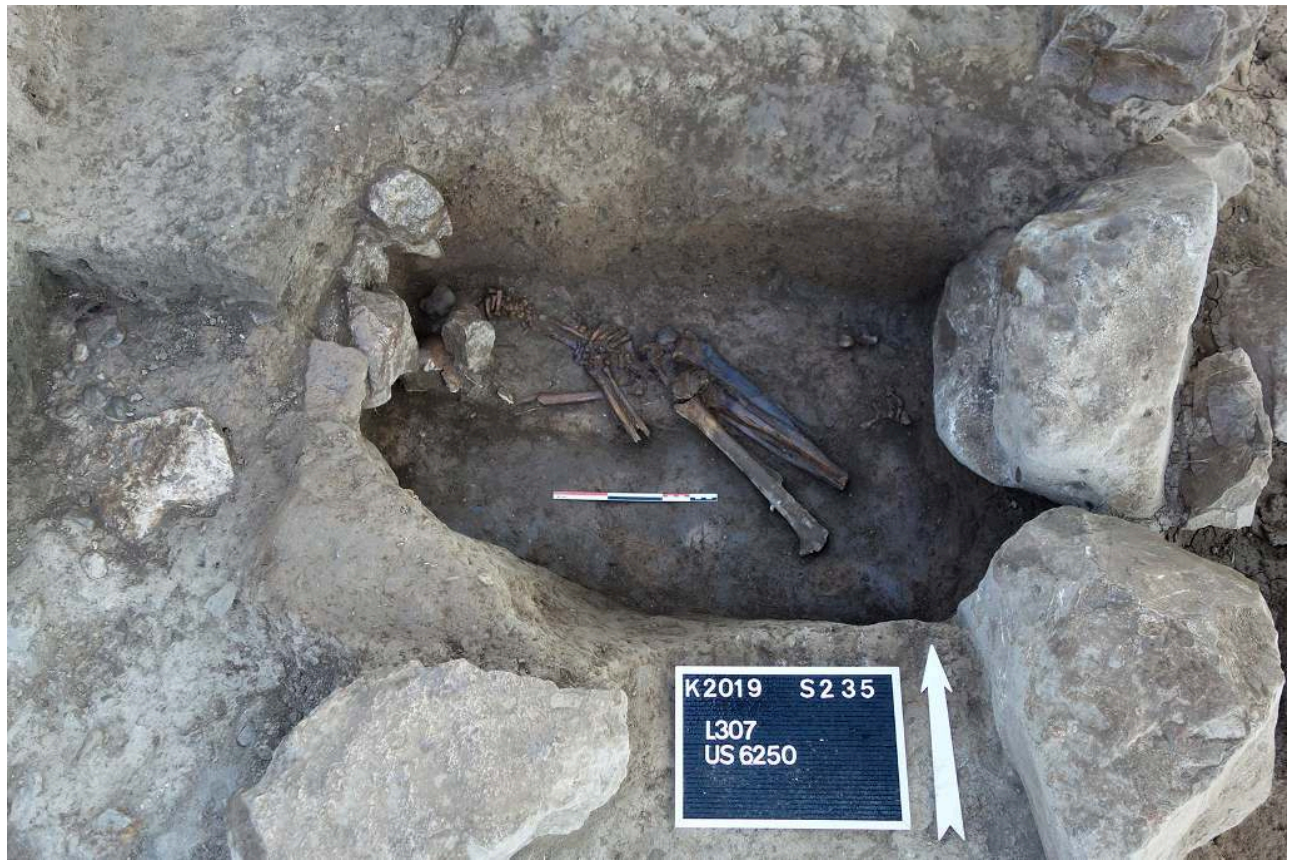

S. Sedlbauer, EFA/Mission Kirrha.

Enfin, cette campagne a également permis de poursuivre la fouille des murs L270 et L269 sous-jacents au soubassement L272 possiblement contemporain des derniers états architecturaux de l'édifice 5.1. Le retour vers l'Est de cet espace est formé par un mur (L313) de facture architecturale analogue, constitué de pierres de gros module et dont l'orientation est strictement parallèle au mur L269. L'interprétation de cet espace de grandes dimensions qui ne trouve pour le moment aucune comparaison formelle à l'échelle du site pose question. En effet, l'agencement même des pierres, pour certaines disposées de chant, sous la forme d'un unique parement, ne semble pas compatible avec une élévation en brique de terre crue. Ces murs pourraient plus vraisemblablement avoir délimité un espace ouvert. La découverte d'une ciste en brique de terre crue (L314) entourée d'une corolle de pierre s'intégrant parfaitement dans l'angle SudOuest formé par les murs L269 et L270 (fig. 15) couplée à la présence d'une importante sépulture secondaire (L 274) située presque au centre, à laquelle succède exactement au même emplacement une inhumation primaire richement dotée (L510-515), inciteraient, à titre d'hypothèse, d'y reconnaître un espace enclos à vocation funéraire (fig. 16). 
Fig. 15. Vue de la ciste L314 implantée dans l'angle Sud-Ouest de «l'enclos » formé par les murs L269, L270 et L313, depuis l'Ouest.

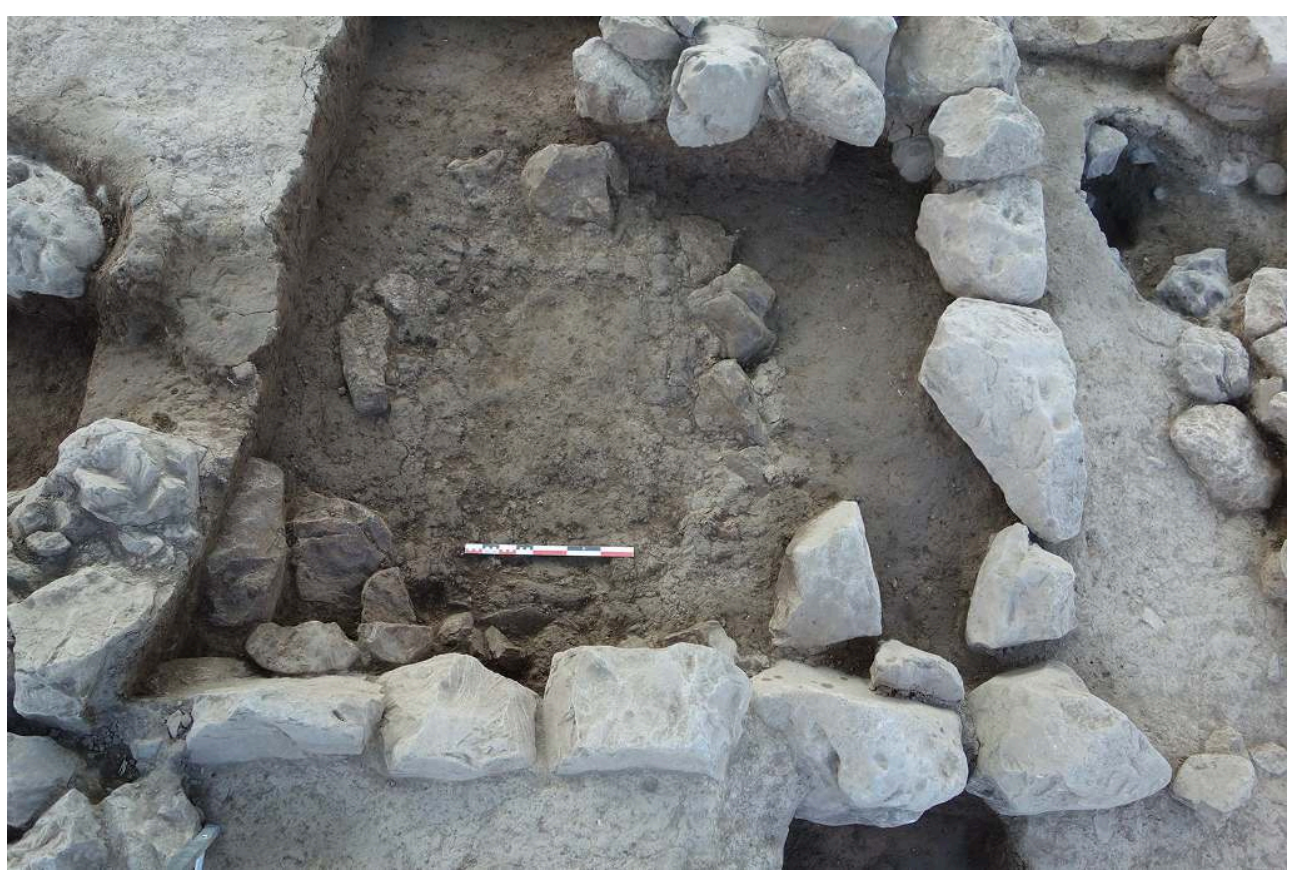

S. Sedlbauer, EFA/Mission Kirrha.

Fig. 16. Plan de la zone de l'hypothétique « enclos funéraire » formé par les murs L269, L270 et L313.

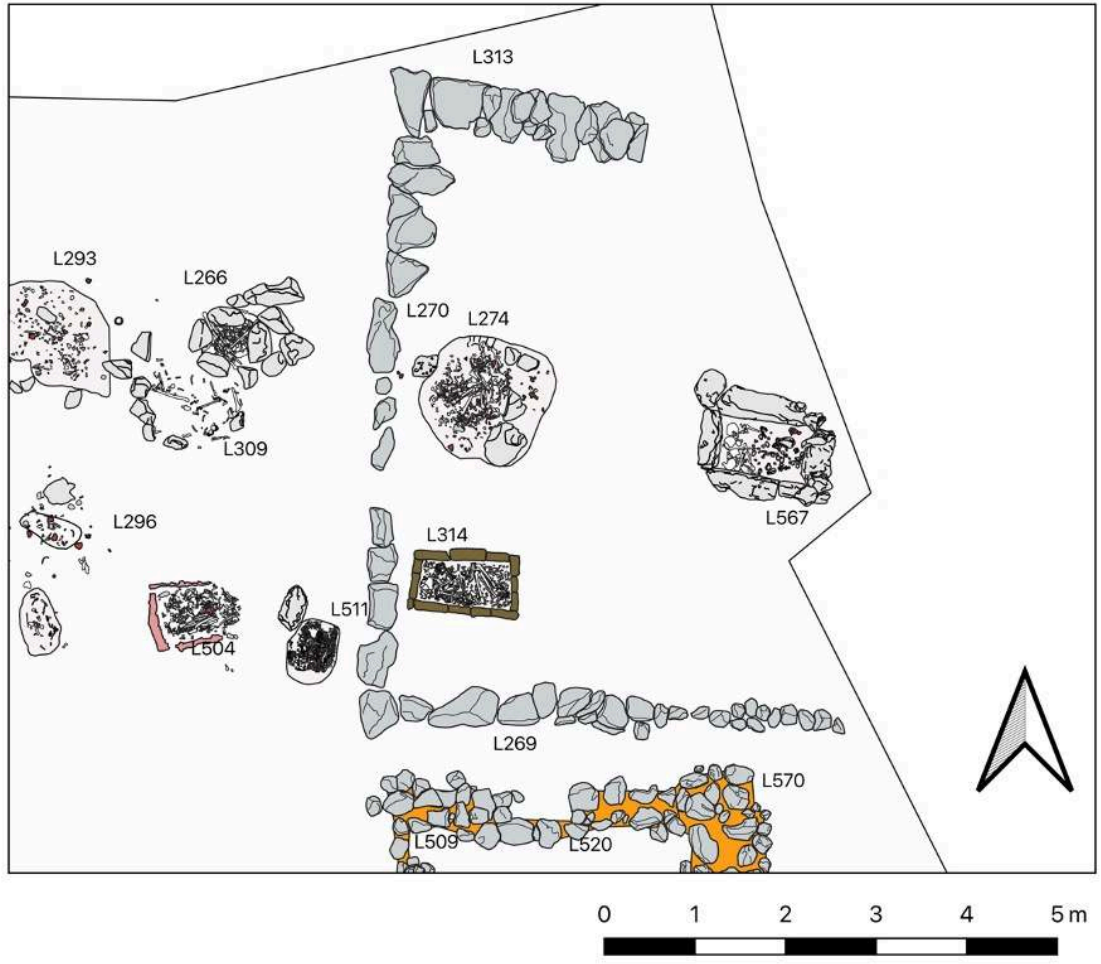

R. Orgeolet, EFA/Mission Kirrha. 


\section{Phase C : la nécropole, données bio-anthropologiques}

La fouille d'un certain nombre de contextes funéraires n'avait pas pu être achevée en 2018 ; c'est désormais chose faite pour les sépultures secondaires L274, L266 et L261, ainsi que la ciste L258. Par ailleurs, le contexte funéraire secondaire L504, dont une petite partie avait été dégagée en 2014, a été cette année entièrement exploré.

Parallèlement, plusieurs tombes et structures funéraires ont été mises au jour et entièrement fouillées cette année. C'est le cas des cistes L283, L293 et L314, de la fosse L295 qui accueillait une réduction, de l'inhumation infantile primaire L288, et enfin des dépôts secondaires L289, L290, L296 et L309. La synthèse des travaux anthropologiques menés cet été dans la nécropole du secteur 235 est présentée dans les paragraphes qui suivent.

L258

Fig. 17. Plan des locus L258 et L261.

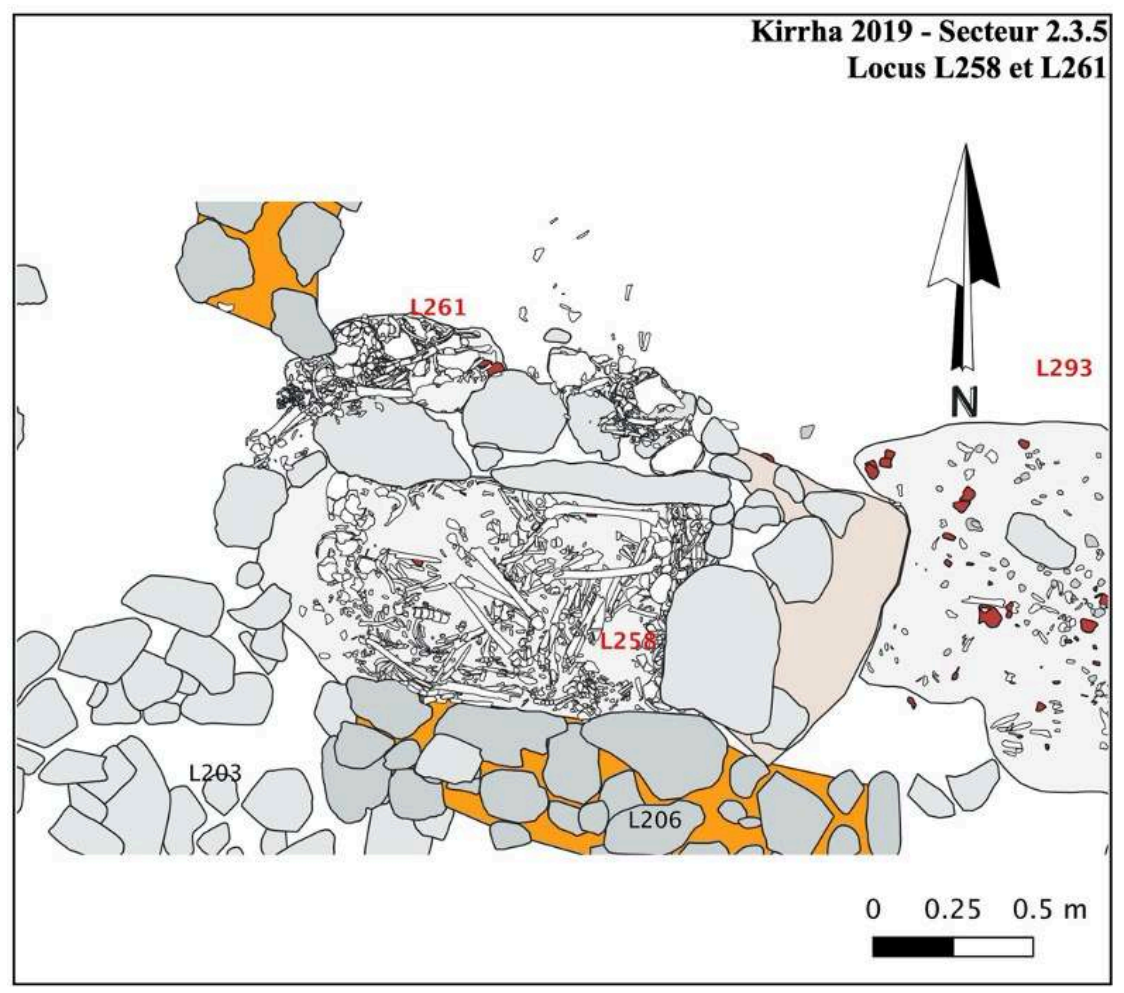

R. Orgeolet, EFA/Mission Kirrha.

La tombe $\mathrm{L} 258$ est une ciste de taille moyenne ( $\mathrm{L} 1,60 \mathrm{~m} ; 1.0,80 \mathrm{~m}$ ) manifestement installée dans l'angle d'une construction antérieure formée par les murs L206 et L291 (fig. 17). Elle accueillait des inhumations multiples très fragmentaires, la tombe ayant manifestement subi des dommages importants après ensevelissement, comme en témoigne le déplacement de l'orthostate du petit côté oriental. Malgré ce morcellement important, le fragment osseux y demeure relativement solide et intègre. La fouille de 
cette tombe avait été entamée lors de la campagne 2018, et trois passes ont été faites réalisées cette année :

- deux passes s'inscrivant dans la continuité de 2018 (dépôt osseux US6167 = US6074 de 2018 et comblement US6166);

- une passe sous la dalle basculée à l'Est concernant le dépôt osseux US6286 et le comblement US6285.

Lors de cette campagne, cinq individus semblent se différencier si nous prenons en compte le NMI (Nombre Minimum d'Individus) strict de terrain. En effet, nous avons pu déterminer avec certitude la présence de «doublons »: deux crânes adultes, deux mandibules adultes, deux rachis adultes, cinq ulnas adultes, deux crânes immatures avec des dents.

Dans ces trois passes, le positionnement des ossements met ainsi en évidence deux possibles dépôts primaires d'adultes (dans ce cas perturbés ou bien non plus primaires mais secondarisés par simple déplacement pour faire de la place alors que la décomposition n'était pas très avancée), deux réductions probables d'immatures et des réductions d'adultes. Toutefois, l'organisation des ossements semble témoigner d'une logique de dépôt plus complexe et une probable multiplicité des individus :

- à l'Ouest, deux mandibules indiquent la position d'au moins deux crânes dans cette zone :

- un crâne toujours en place et très fragmenté présente sa face vers le Nord et pourrait potentiellement avoir conservé sa mandibule (logique de proximité) mise à plat mais retournée dans son sens proximal/distal ;

- une seconde mandibule mise à plat apparait plus au Sud et dans le bons sens ;

- dans la moitié Sud, deux colonnes vertébrales se distinguent :

- dans la partie la plus centrale, un premier groupe de vertèbres thoraciques en connexion étroite présente la face antérolatérale droite des corps vertébraux, illustrant une légère torsion, tandis que des côtes peuvent être observées dans une logique de connexion;

- plus au Sud, plusieurs groupes de vertèbres semblent esquisser la présence d'une colonne vertébrale, des cervicales aux lombaires, qui pourrait avoir été poussée au Sud au cours de la décomposition;

- contre la paroi Nord, sont distingués deux bras gauches dont l'un est plié dans l'espace du corps avec la main posée à plat (décubitus dorsal ? décubitus latéral droit ?) ;

- contre la paroi Sud, ce sont deux bras droits dont l'un des deux est en miroir du bras gauche, plié dans l'espace du corps, et ayant conservé une connexion logique avec la clavicule droite ce qui pourrait faire penser à un dépôt primaire en décubitus dorsal ;

- deux fémurs manifestement déplacés et retournés dans leurs sens proximal/distal et antérieur/postérieur ;

- un pied laissé en place au Nord-Est et identifié par la connexion logique de ses métatarses et de quelques phalanges;

- deux réductions en fagot :

- des membres inférieurs dans le second quart Est ;

- des membres inférieurs et supérieurs (dont un cinquième ulna) et d'autres ossements contre la paroi Est et sous la dalle basculée ;

- deux immatures qui ont été prélevés en motte afin de privilégier l'étude de ces individus en laboratoire et réduire le risque de perte d'information:

- à l'Ouest des fragments de crâne et de mandibule, des dents, des vertèbres et des côtes sont retrouvés sous le crâne adulte ;

- au Sud-Est des fragments de crâne et des dents sont retrouvés. 

cotations Schmitt sur un coxal gauche mis à jour sous le fagot d'os longs contre la paroi Est et qui indiqueraient un individu âgé entre 20 et 49 ans (valeur en testant tous les scores du quatrième caractère SSPID). Les individus présents dans la ciste ne présentant pas de pathologie ou variation anatomique apparente nous évoquent des adultes jeunes. Enfin, les ossements demeurent trop fragmentés pour prétendre utiliser les mesures des os longs pour déterminer une stature.

\section{L261}

Fig. 18. Photographie des locus L258 et L261 depuis le Nord. En bas, le Locus L261B à la passe 8.

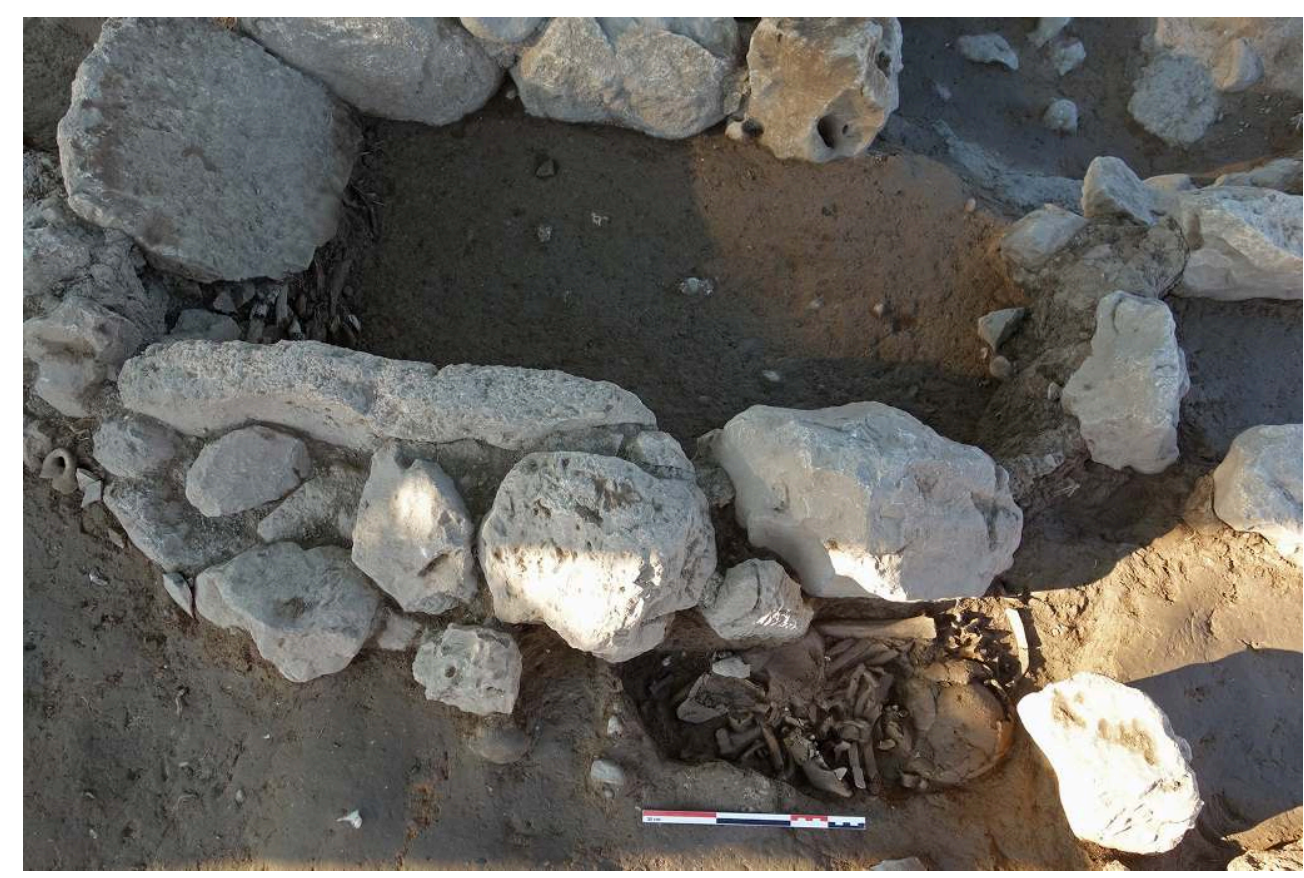

S. Sedlbauer, EFA/Mission Kirrha. réductions déposées contre la paroi Nord de la ciste L258 (fig. 18) ainsi qu'un vase retrouvé reposant contre la limite de fosse Est et la paroi Nord. Cette année, quatre passes ont été réalisées : 6, 7, 8 et 9 avec une remise à zéro au démontage (1 à 105) pour mettre à jour le dépôt osseux (US 6241) et le comblement (US 6240).

Des limites de fosse apparaissent au Nord avec de petites inclusions blanches et rouges, au Nord-Est avec un sédiment plus rose et plastique et à l'Ouest avec l'apparition de petits cailloux. Le sédiment reste par ailleurs homogène malgré quelques inclusions argileuses et de nodules de terre à bâtir ainsi que de petits galets. Enfin, le fond de fosse 
est apparu livrant un sédiment plus meuble et avec plus de petits galets. Notons qu'à partir de la passe 8 , certains ossements sont retrouvés sous une pierre de calage de l'architecture de la ciste L258 ce qui laisse supposer la contemporanéité des deux sépultures.

Pour ces quatre nouvelles passes, le NMI serait de 1 individu adulte. Il sera nécessaire de confirmer l'état sanitaire en laboratoire car seul un humérus droit (P.9) semble présenter des ostéophytes, ce qui suggère un adulte jeune. Au cours de ces passes, et mise à part la mise en fagot de la plupart des os longs, aucune organisation particulière ne semble se détacher.

L266

51 La tombe L266 est une petite ciste faite de moellons de taille moyenne, qui délimitent un espace rectangulaire d'environ $40 \times 30 \mathrm{~cm}$ (fig. 19 et 20). Il est apparu, au cours de la fouille du locus L309, que la ciste L266 a été installée dans ce dernier, qu'elle recoupe clairement.

La fouille de la sépulture L266 a débuté en 2018, avec deux premières passes. Les deux passes supplémentaires faites au cours de cette campagne ont permis de clôturer la fouille de ce contexte, et d'estimer à cinq (à partir des crânes) le nombre d'individus déposés dans la ciste. Le comblement est homogène d'une passe à une autre, et peut être décrit comme brun jaunâtre légèrement argileux et meuble, avec des fragments de céramiques de petite taille, quelques petits galets et des silex non taillés.

Fig. 19. Plan des Locus L266 et L309.

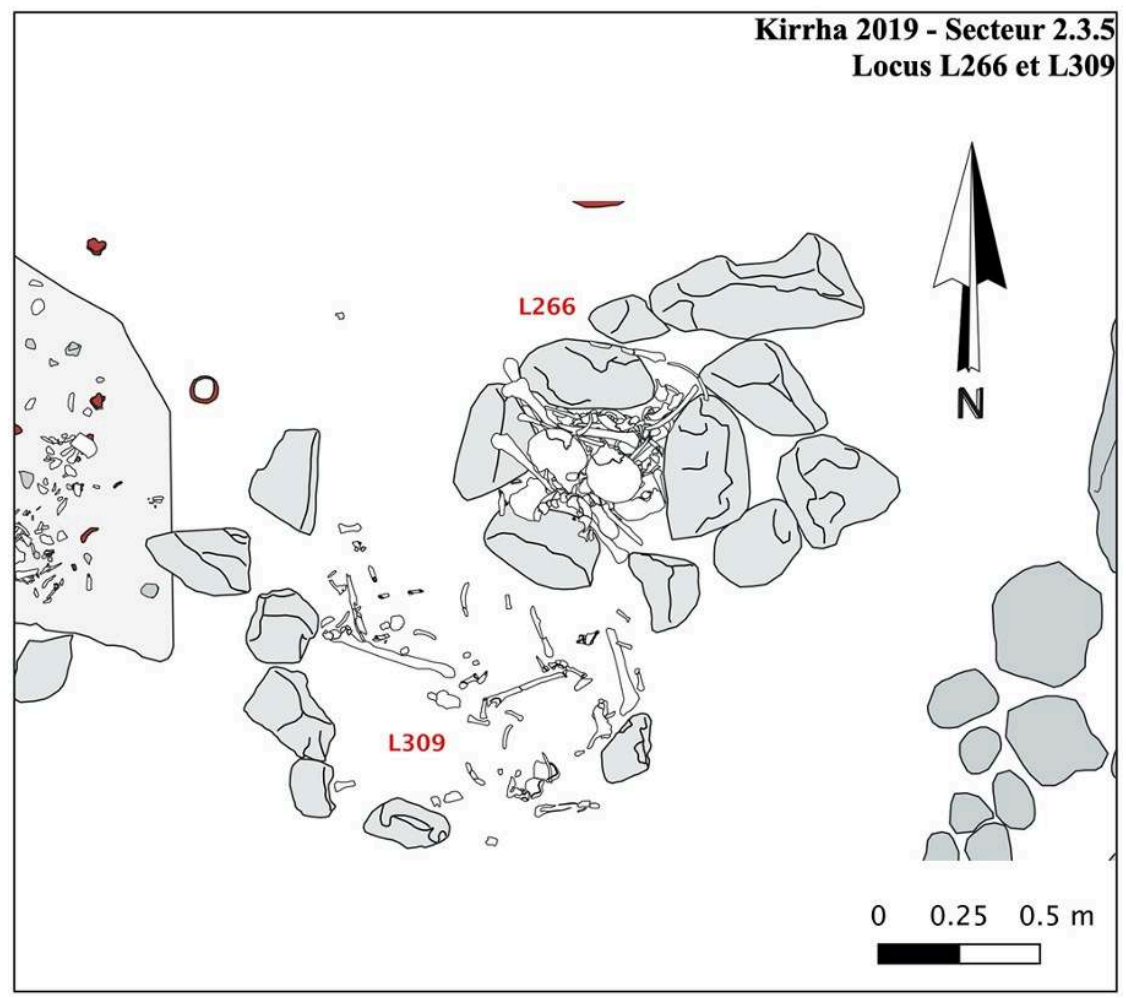

R. Orgeolet, EFA/Mission Kirrha. 
Fig. 20. L266 passe 3.

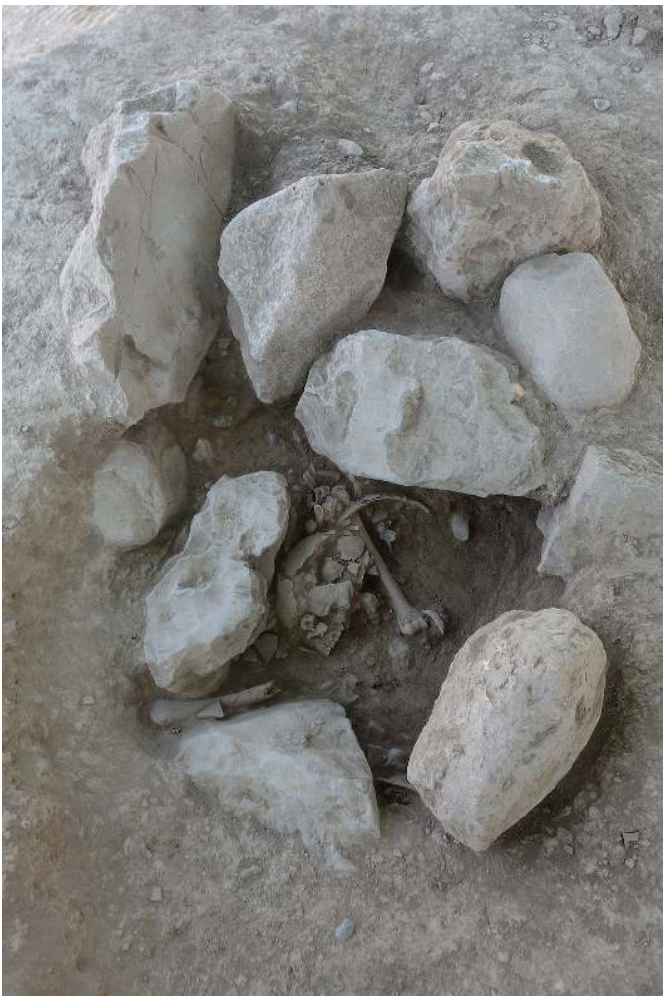

S. Sedlbauer, EFA/Mission Kirrha.

53 Dans l'ensemble, la ciste L266 a été utilisée pour le dépôt d'au moins 5 individus; la fouille de 2019 concerne le premier dépôt de la ciste. En raison de leur installation au fond de la sépulture, les ossements de ce premier dépôt ont souffert de l'installation des quatre autres, ce qu'indiquent les nombreuses fractures anciennes identifiées, mais aussi l'état de dégradation générale des ossements, et particulièrement du crâne. L'absence d'articulation conservée d'une passe à l'autre révèle que les individus étaient déjà à l'état de squelette lors du dépôt.

Aucune organisation des os n'est visible, leur agencement ayant probablement été bouleversé par les dépôts ultérieurs.

\section{L274}


Fig. 21. Plan du Locus L274.

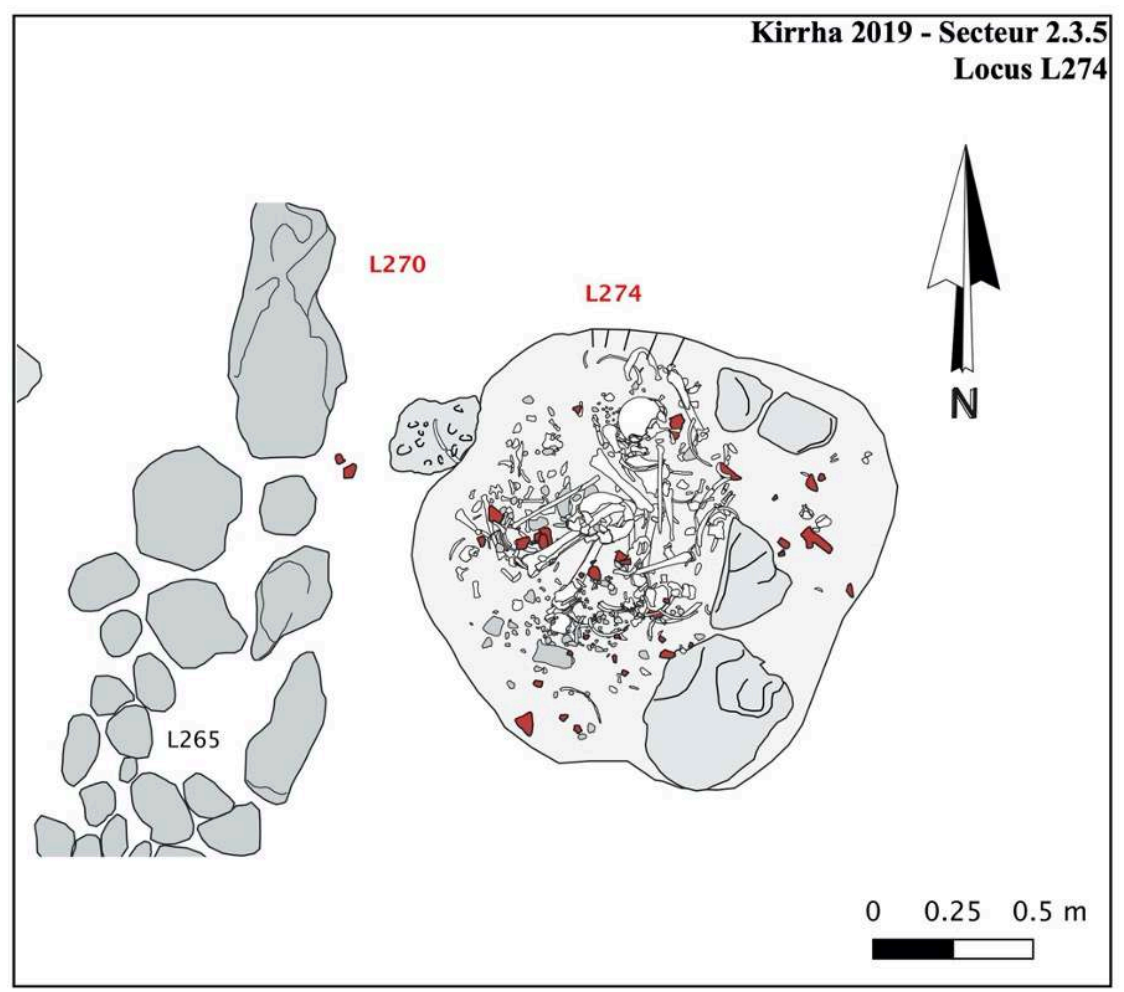

R. Orgeolet, EFA/Mission Kirrha.

55 Il s'agit d'une fosse à inhumations secondaires multiples (fig. 21 et 22), disposée rigoureusement sous la sépulture L510-L515 richement dotée, que nous avions fouillée en 2015 à cet emplacement.

La fouille du contexte L274 avait débuté en 2018 et a été achevée en 2019 ; neuf passes ont été effectuées au total, dont deux en 2018. Les limites de la fosse ne sont pas clairement établies faute de lisibilité claire du sédiment.

Le comblement des passes 1 à 7 est le même, il est de nature argileuse, jaune-grisâtre et hétérogène, avec des inclusions de galets, de malacofaune, d'argile et plus rarement de charbons. Apparaissent également de manière ponctuelle des fragments de céramique et de la faune. 
Fig. 22. Photographie du Locus L274 à la passe 6.

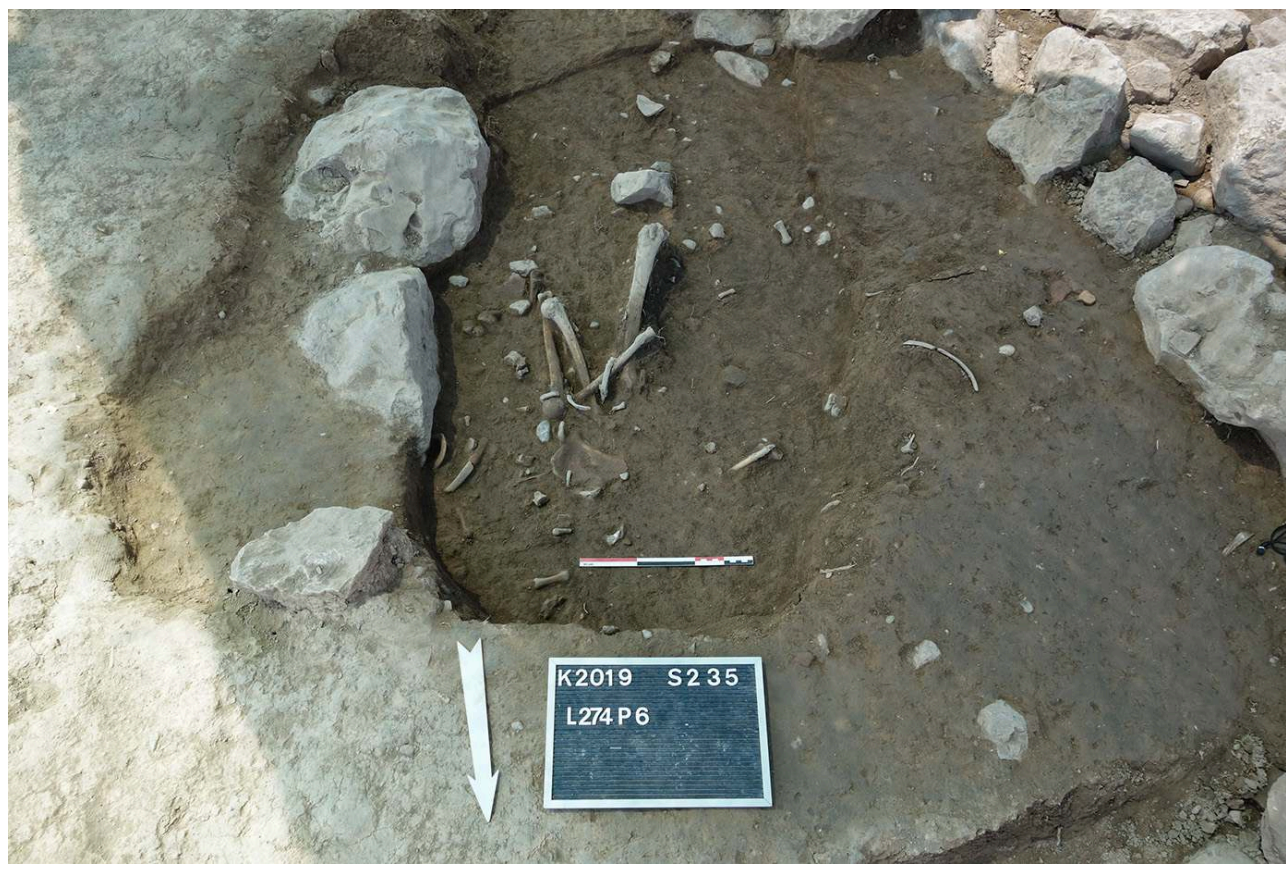

S. Sedlbauer, EFA/Mission Kirrha.

58 La chronologie des dépôts dans L274 peut être restituée comme suit : premièrement, un adulte et un non-adulte en réduction, déposés dans une fosse peu profonde dont les limites sont outrepassées dans la partie supérieure. Si la détermination des limites précises du creusement de la grande fosse (US 6275) a posé problème, l'éparpillement des ossements de cette première déposition plurielle tend à montrer que ce creusement préexistait, peut-être avec une étendue moindre, notamment dans la partie sud. Cette réduction conjointe des deux individus laisse peu d'indices concernant une organisation quelconque du dépôt, si ce n'est le fait que le crâne adulte soit déposé sur deux fémurs.

59 La seconde étape de l'occupation de ce contexte intervient alors que le comblement de la première sépulture est déjà total, mais dans un laps de temps qu'il est impossible de quantifier. Ce second dépôt obéit aux mêmes critères que le premier : réduction d'un adulte et d'un non-adulte, ici plus précisément un adolescent. La concentration des ossements en passe 7 ainsi que la déclivité des os longs visible dès la passe 3 pourrait être le témoignage d'un dépôt dans un creusement peu profond, ici aussi outrepassé dans la partie supérieure. Dans cette seconde étape, la simultanéité des deux dépôts est très probable, comme le montre l'enchevêtrement des os longs des deux individus dans la partie Sud. L'agencement des os est limité aux côtes déposées « en éventail » au Sud.

60 Pour cette seconde réduction comme pour la première, le volume déposé dépasse largement le creusement peu profond initial. Les os les plus petits sont, dans le premier cas, déposés pêle-mêle dans la partie supérieure de la réduction, et pour le second dépôt, déposés en amas contre la paroi Nord Est de la fosse.

61 Une troisième étape consiste dans l'extension de la grande fosse au Nord-Est pour le dépôt du dernier dépôt secondaire en réduction d'un seul individu, dont la fouille a été essentiellement réalisée en 2018. 
62 La fouille de 2019 sur le contexte L274 a permis d'éclaircir certains points laissés en suspens à la suite de la campagne de 2018, et d'en préciser d'autres. En premier lieu, l'hypothèse d'un seul et unique creusement occupé et réaménagé à plusieurs reprises, présentée en 2018, se vérifie, mais dans une configuration plus complexe. En effet, dans le cas des deux premiers dépôts, il semble qu'une partie au moins des ossements soit installée dans un léger creusement que le dépôt en lui-même excèdera rapidement. Toutes ces hypothèses doivent naturellement attendre confirmation ou infirmation par l'étude des ossements de l'ensemble en laboratoire.

À partir de la passe 3, aucune connexion anatomique conservée n'a été observée, et l'organisation des ossements au sein de chacun des dépôts reste minime.

64 À l'issue de la passe 2, en 2018, il n'était pas clair si le dépôt correspondait à une inhumation primaire bouleversée, ou bien de dépôts secondaires déplacés dans cette fosse. Or, à l'exception des de la connexion observée en 2018 entre l'atlas et l'axis (et une troisième de manière plus hypothétique), aucun autre ossement n'a été retrouvé en connexion. Dès lors, le dépôt (US 6164) est plus vraisemblablement un dépôt secondaire. Cependant, la conservation de la connexion atlas / axis dans de l'un des deux individus interroge la temporalité avec laquelle celle-ci s'est effectuée après la mort du défunt.

Le NMI du locus L274 est estimé d'après les observations réalisées sur le terrain de 6, dont un immature dans le dépôt de l'US 6164, représenté par quelques os, et qui ne pourrait être que résiduel ou lié au déplacement de l'ensemble des ossements. Ces données seront précisées à la suite de l'étude anthropologique. La répartition des individus dans les deux dépôts doubles est, dans les deux cas, celle d'un adulte et d'un non-adulte. 
Fig. 23. Plan des Locus L283 et L290.

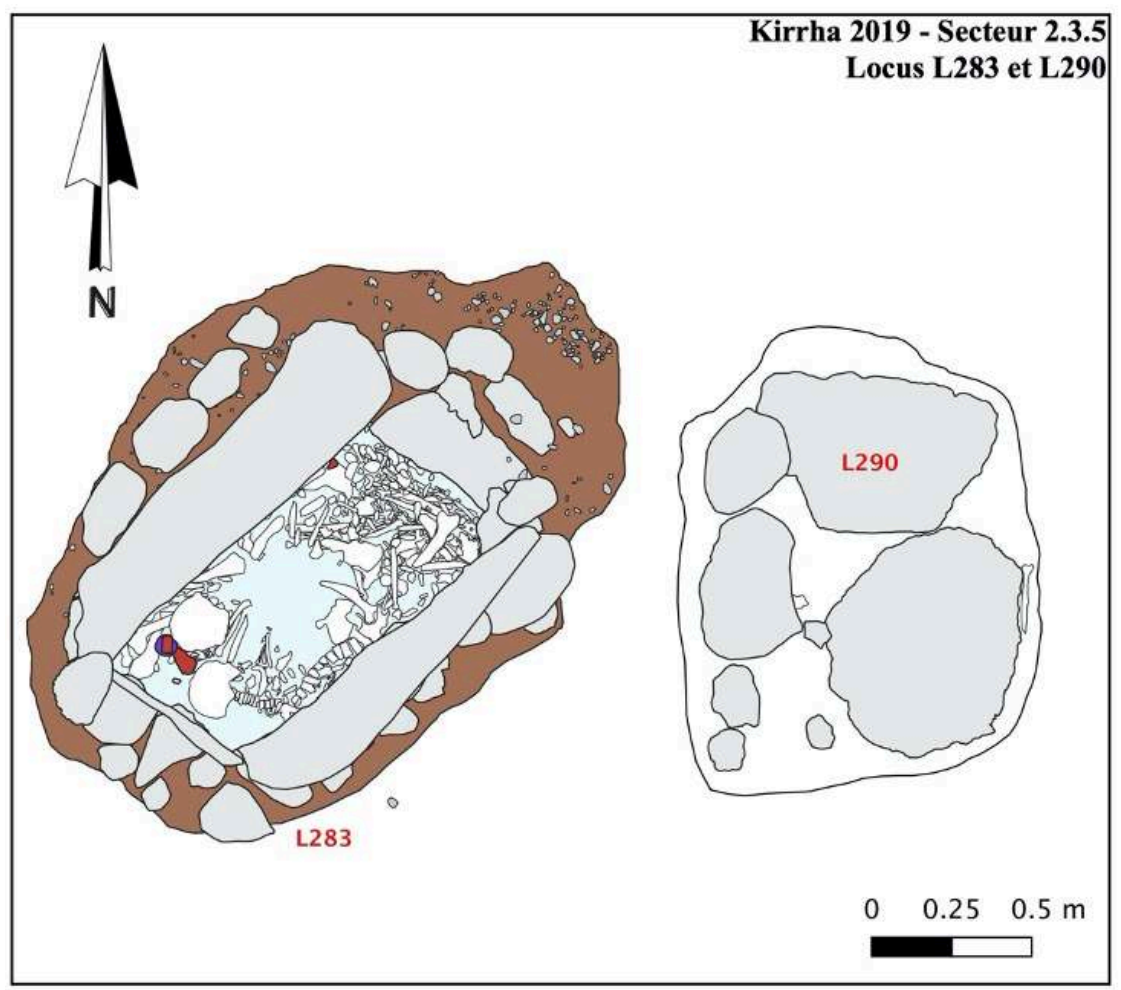

R. Orgeolet, EFA/Mission Kirrha.

La tombe L 283 a été mise au jour lors de la campagne 2018, ouverte et fouillée en 2019 (fig. 23). Il s'agit d'une tombe à ciste à orthostates $(1,15 \mathrm{~m} \times 0,60 \mathrm{~m}$-dimensions intérieures au niveau du lit de pose des ossements) constituée d'une dalle par côté, d'une petite assise de réglage sur deux côtés et d'un couvercle imposant fait d'une grande pierre calcaire et de quelques pierres de calage (fig. 24). Elle est installée dans une large fosse ovale $(2,15 \mathrm{~m} \times 1,45 \mathrm{~m})$, l'espace intermédiaire étant comblé de sédiment et de pierres de gabarit moyen. Les ossements dans la tombe étaient recouverts d'une fine terre d'infiltration ne remplissant pas la totalité de l'espace vide du coffrage (fig. 25). 
Fig. 24. Vue de la tombe L283 avec son dispositif de couverture.

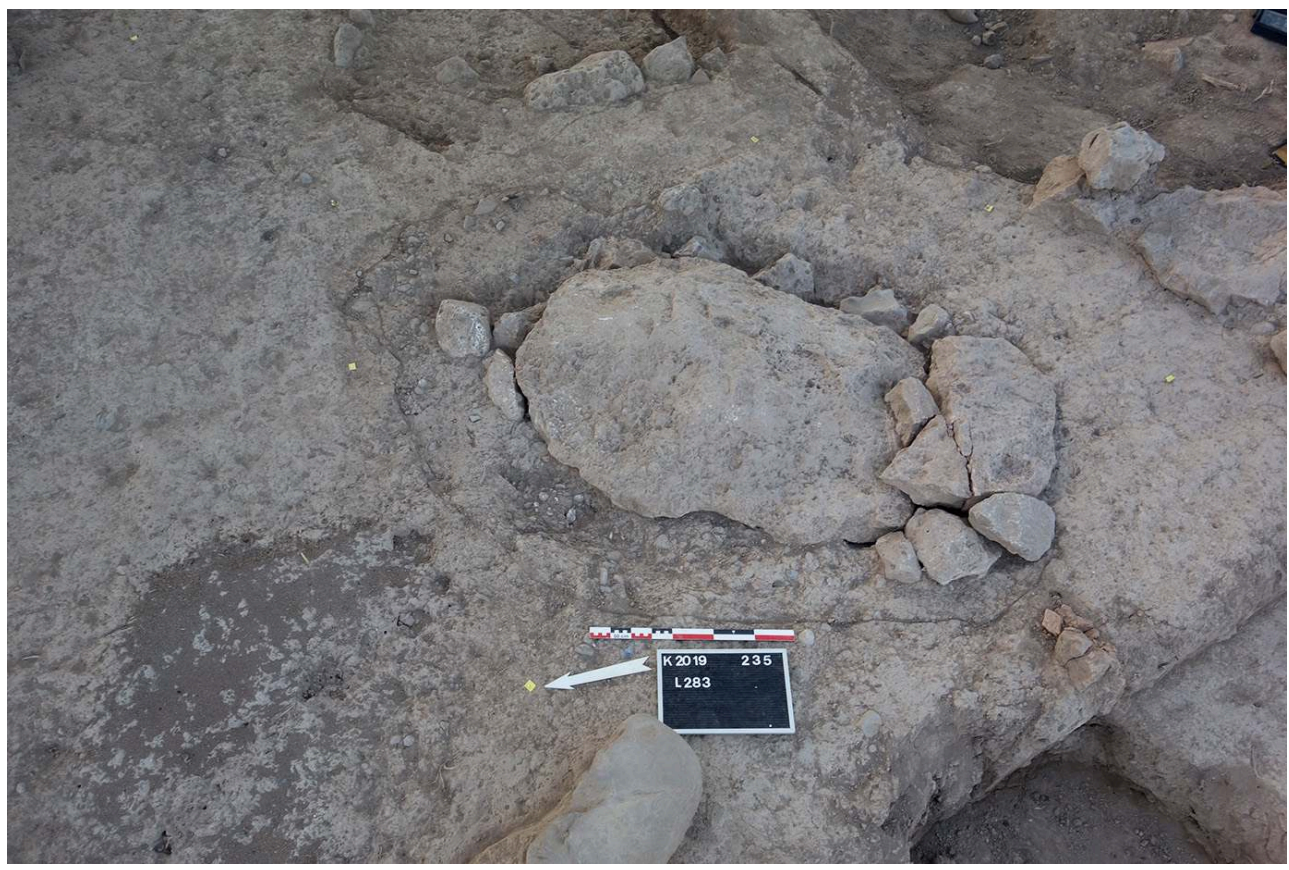

EFA/Mission Kirrha

Fig. 25. Tombe L283 après enlèvement du dispositif de couverture et du remblai associé, et dégagement des dépôts d'ossements.

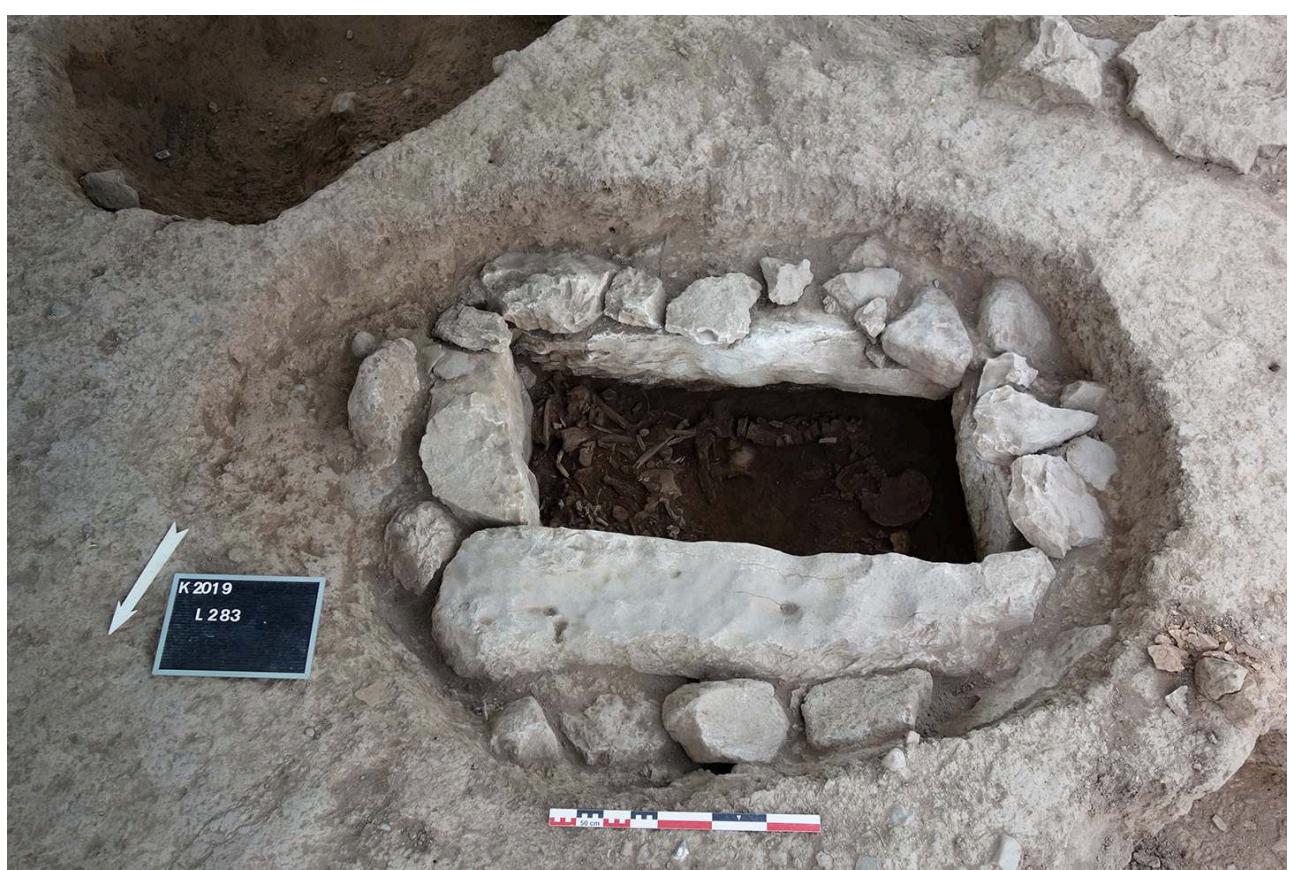

EFA/Mission Kirrha.

Cette tombe est une sépulture collective ayant reçu un dépôt primaire et deux dépôts secondaires, totalisant un minimum de 4 individus (fig. 26). Le dernier individu inhumé en position primaire, identifié à une femme adulte, était en position fléchie allongée sur le côté gauche dans l'orientation de la tombe, la tête à l'Ouest / Sud-Ouest. Les deux amas secondaires identifiés à des réductions étaient disposés dans les espaces 
disponibles de la tombe (contre le petit NE et la dalle NO), recouvrant en partie le squelette en position primaire. Aucune connexion anatomique n'a été observée dans ces deux dépôts secondaires. En revanche, on notera d'une part, un volume d'ossements plus important pour la réduction du côté NE et, d'autre part, l'agencement particulier des os longs regroupés en fagots sur le lit de pose dans les deux cas. L'ensemble des ossements identifiés pour ces dépôts secondaires sont matures et correspondent à un minimum de 3 individus au sexe indéterminé : deux individus réduits bien représentés à la différence du troisième largement sous-représenté, témoignant d'un traitement différencié.

La fouille de cette tombe a livré trois objets. Un petit vase à anse en panier a été retrouvé en position inversé dans la partie sud-ouest de la tombe. Situé non loin du crâne de l'individu primaire, il était recouvert par un os de la réduction et ne peut donc être clairement associé à l'un ou l'autre dépôt. En revanche, le second objet, une fusaïole en pierre, a été retrouvée sous le crâne de l'individu primaire. Enfin, un troisième objet indéterminé a été trouvé dans l'angle Ouest sous les os de la réduction placée à cet endroit.

Fig. 26. Tombe L283.

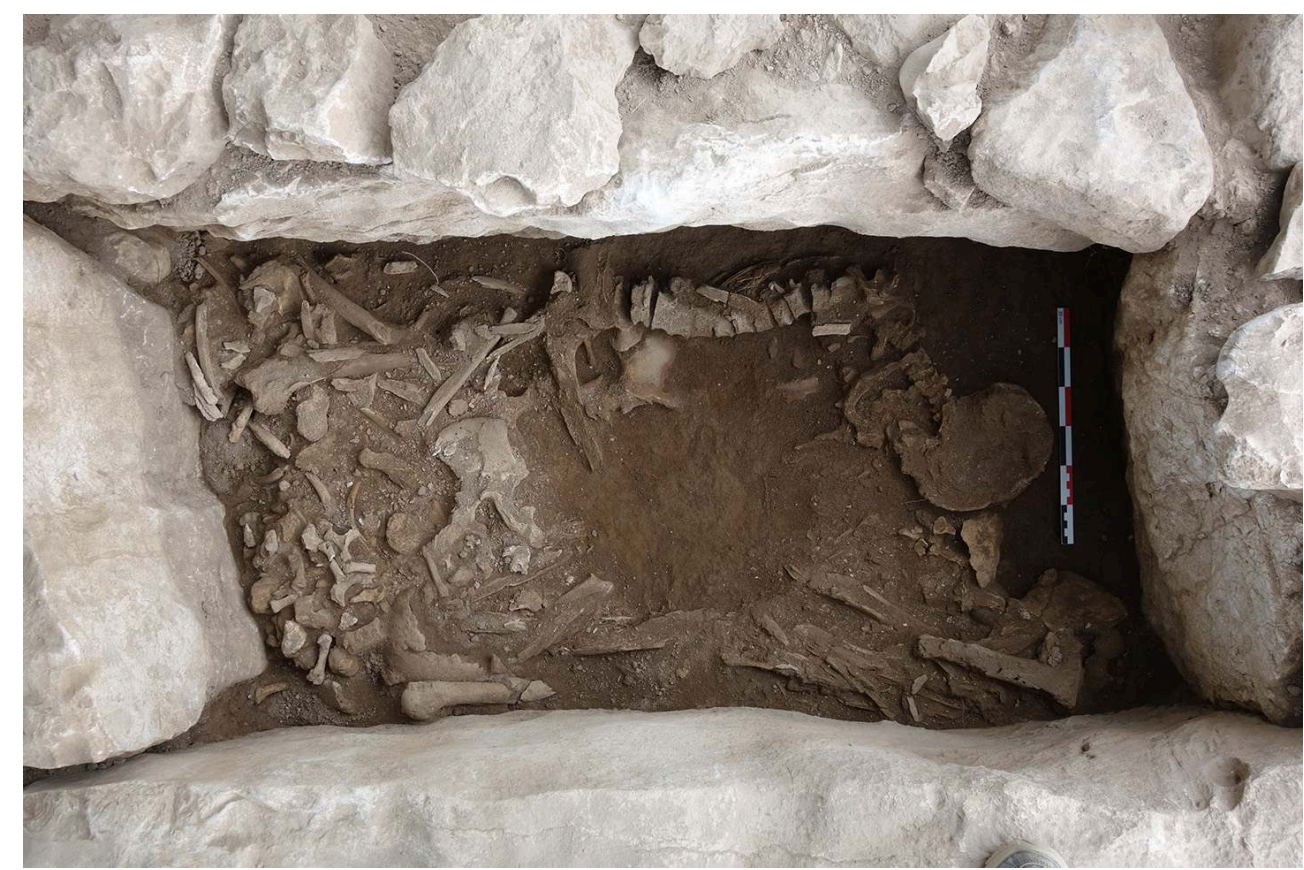

Vue des dépôts funéraires à l'intérieur de l'espace de la ciste depuis le nord-est : au sud le dépôt primaire, contre le petit côté nord-est et dans l'angle ouest, les deux dépôts secondaires.

EFA/Mission Kirrha. 
Fig. 27. La sépulture L288 vue depuis l'Ouest.

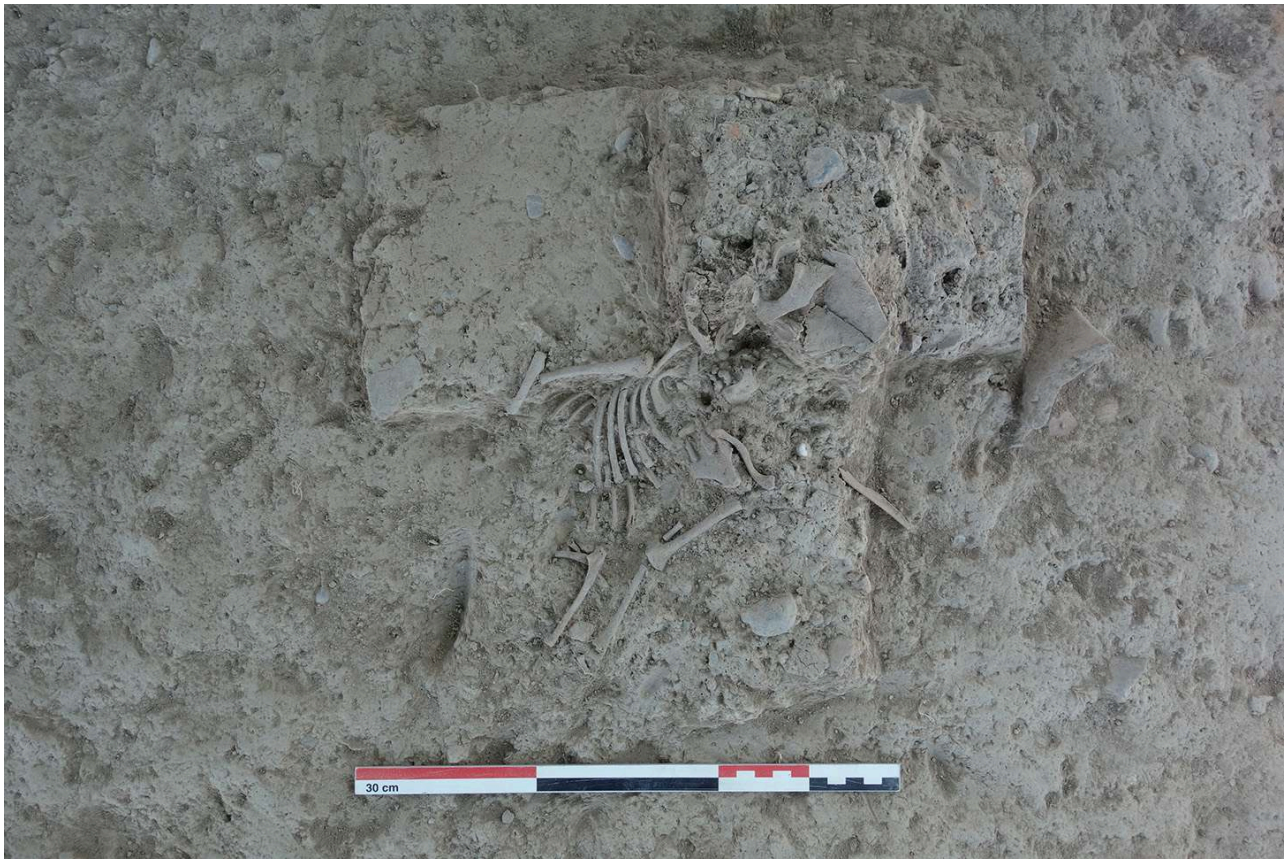

M. De Jonghe, EFA/Mission Kirrha

69 Le contexte L288 est une inhumation primaire individuelle d'un immature installée dans une fosse peu profonde. En raison de la nature du sédiment, la fosse n'a pas été identifiée, et les membres inférieurs ont été déplacés au moment de la découverte (fig. 27). À l'exception du crâne, et en tenant compte de l'absence des membres inférieurs, on peut dire que les ossements sont dans l'ensemble dans un très bon état de conservation, et n'ont pas subi de détérioration.

On observe une mise à plat des volumes, notamment au niveau de la cage thoracique. Les côtes inférieures droites ont été retrouvées en dehors du volume initial du corps. La position du radius gauche semble être le résultat d'un basculement au cours de la fouille, l'empreinte de son emplacement d'origine est toujours visible à gauche de l'humérus sur les photographies. Ainsi repositionné, on observe un léger alignement des membres supérieurs gauches, alors que l'articulation de l'épaule est, elle, déconnectée. Sous la cage thoracique, les trois premières vertèbres identifiées ne sont pas en place et plongent vers la base du crâne. On observe ensuite un bloc de cinq vertèbres en connexion, tandis que les suivantes ont subi une disjonction par rotation ayant entrainé la séparation du corps et des épiphyses. L'alignement des membres supérieurs gauche, le déplacement des côtes inférieures droites ainsi que la disjonction des vertèbres, pourraient indiquer une décomposition en espace vide. Cependant, la nature de celui-ci est difficile, voire impossible à caractériser. Le reste des mouvements osseux se faisant à l'intérieur du volume corporel, il semble que le comblement soit néanmoins intervenu rapidement après le dépôt du corps, ne plaidant pas réellement en faveur d'un contenant en matière périssable, mais davantage un élément textile qui aurait enveloppé le corps, ou bien d'espaces vides internes ayant persisté malgré un comblement direct.

71 La position des côtes donne une impression a priori d'un dépôt du corps en décubitus latéral, mais les membres supérieurs indiquent davantage un décubitus dorsal, de 
même que la position du maxillaire supérieur droit. Celui-ci est élevé par rapport au reste du corps, il n'y a pas d'effet de basculement observé. La mandibule est absence et ne permet donc pas de compléter ces informations.

Le crâne est particulièrement en mauvais état, les fontanelles n'ont pas résisté au poids des sédiments. L'une des cavités orbitales disjointe est visible dans la partie $\mathrm{S}$. de l'emplacement du crâne.

L290

Fig. 28. L290 en cours de fouille.

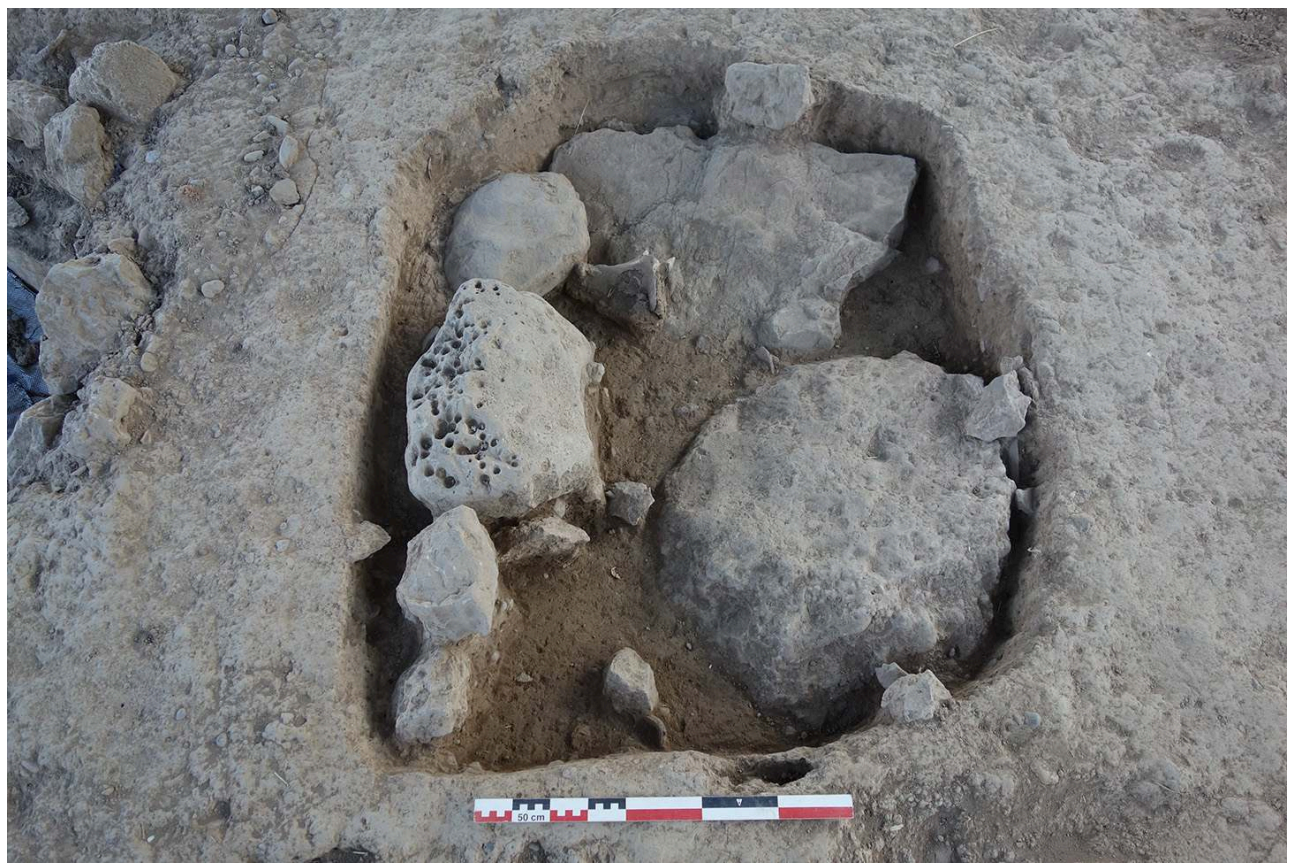

EFA/Mission Kirrha

Le contexte L290 est constitué d'une fosse sub-rectangulaire aux angles arrondis, mesurant 1,48 $\mathrm{m}$ de longueur, 1,08 $\mathrm{m}$ de largeur et 0,35 $\mathrm{m}$ de profondeur (fig. 23 et 28). $\mathrm{Au}$ fond du creusement sont installés deux grandes dalles, et au-dessus de celles-ci, s'aligne le long de la paroi Ouest du creusement quatre blocs.

Le comblement du creusement est meuble dans l'ensemble, et plus friable par endroits, de couleur brun-jaunâtre. $\mathrm{Y}$ apparaissent de la faune et de la céramique en petite quantité. Le contexte est mis en lien avec l'utilisation funéraire de la zone par la présence dans ce comblement de quelques ossements adultes ramassés contre les pierres situées à l'Ouest: une clavicule gauche, bougée au cours de la fouille, un métatarse droit, une scapula droite et un tibia droit. Ce dernier est situé de l'autre côté de la fosse, entre la paroi Est du creusement et la dalle. Tous les ossements sont retrouvés en plan horizontal.

75 Un second comblement, US 6211, tapissait le fond du creusement. Dans l'angle NordOuest de cette couche, un fragment de calotte crânienne a été retrouvé.

L293 
Fig. 29. Plan du Locus L293.

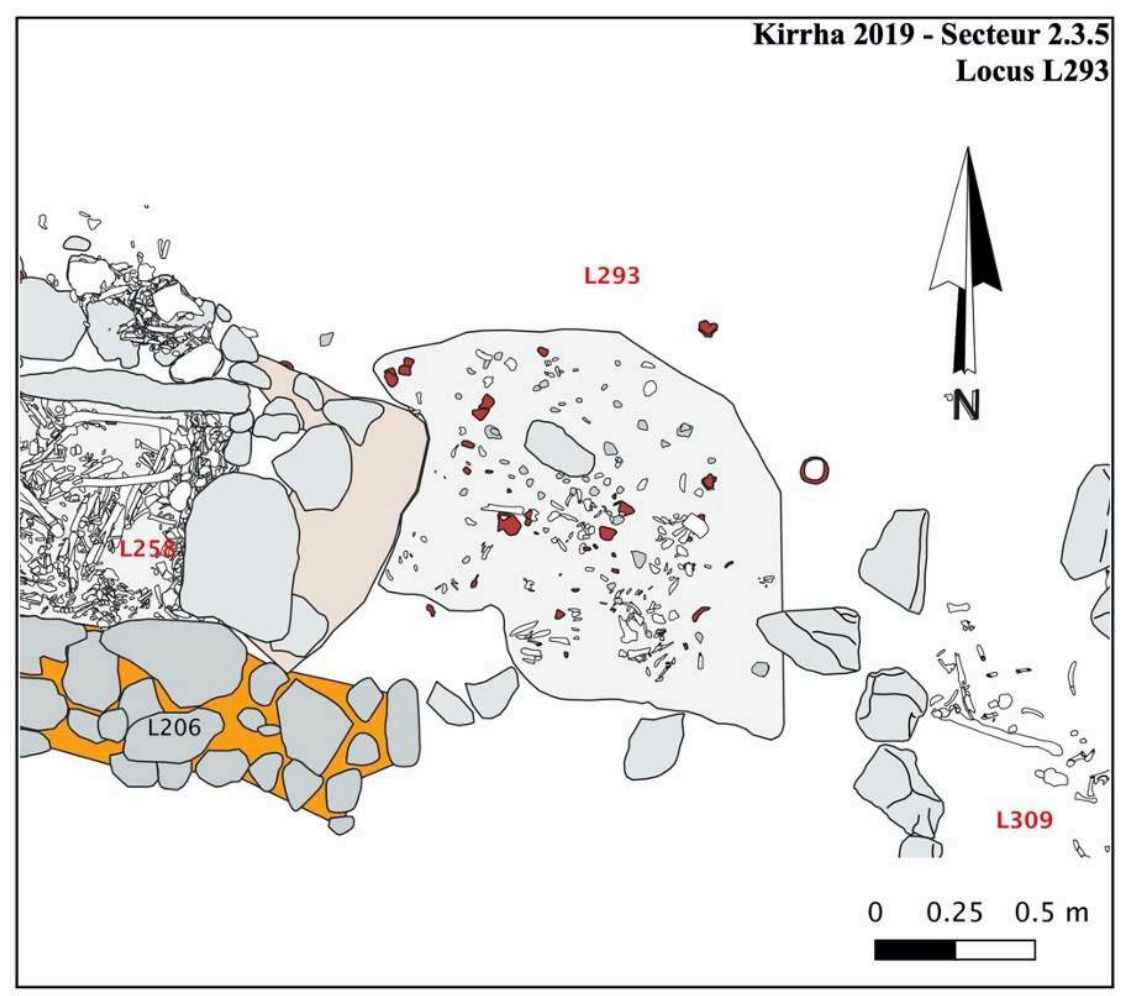

R. Orgeolet, EFA/Mission Kirrha.

76 Le contexte L293 est une fosse peu profonde de forme irrégulière mesurant $1,39 \mathrm{~m}$ de longueur et 1,15 m de largeur, globalement orientée Est-Ouest (fig. 29). Elle contenait un dépôt secondaire en réduction. Le sédiment qui comblait la fosse est limonoargileux, compact, de couleur brun-gris tirant sur le jaunâtre. Il est de nature hétérogène, et contenait des galets, de la faune et quelques pierres. La fouille s'est déroulée en quatre passes, et la première a livré un petit vase.

Les trois premières passes sont marquées par des ossements très fragmentés et dispersés, dont la détérioration rend complexe toute lecture et tentative de synthèse. La quatrième passe en revanche a livré une réduction organisée autour d'un crâne disposé à l'envers, mais la partie supérieure du dépôt est lacunaire et les ossements sont très fragmentaires. La première question qui se pose est celle du NMI: les ossements des premières passes appartiennent-ils à la réduction de la passe 4 ou bien à un autre individu?

La fragmentation du crâne et la localisation des fragments de calotte crânienne identifiés aux passes 1 à 3 tendent vers un seul et même individu; deux si l'on prend en compte le possible ossement immature.

En admettant l'hypothèse d'un seul individu, qui ne pourra être confirmée qu'en laboratoire, deux grilles de lecture sont possibles. Premièrement, un dépôt secondaire en réduction qui aurait subi un bouleversement à une période ancienne ayant entrainé la fragmentation du crâne et l'éparpillement de ces fragments. Cette hypothèse est mise à mal par la présence du vase identifié en passe 1, qui lui aussi aurait dû faire les frais de ce bouleversement. 
La seconde, est que l'agencement des ossements dans la sépulture se fait en deux temps : premièrement les os les plus grands : os long, crâne, côtes, certaines vertèbres, agencés dans une réduction organisée. Puis les ossements de plus petite taille déposés en amas, voire mêlés à la terre du comblement. Configuration que l'on peut observer dans une certaine mesure pour L274. Le vase situé au centre serait alors le témoignage de l'emprise la plus large du dépôt funéraire.

Fig. 30. Plan des Locus L295, L296 et L504.

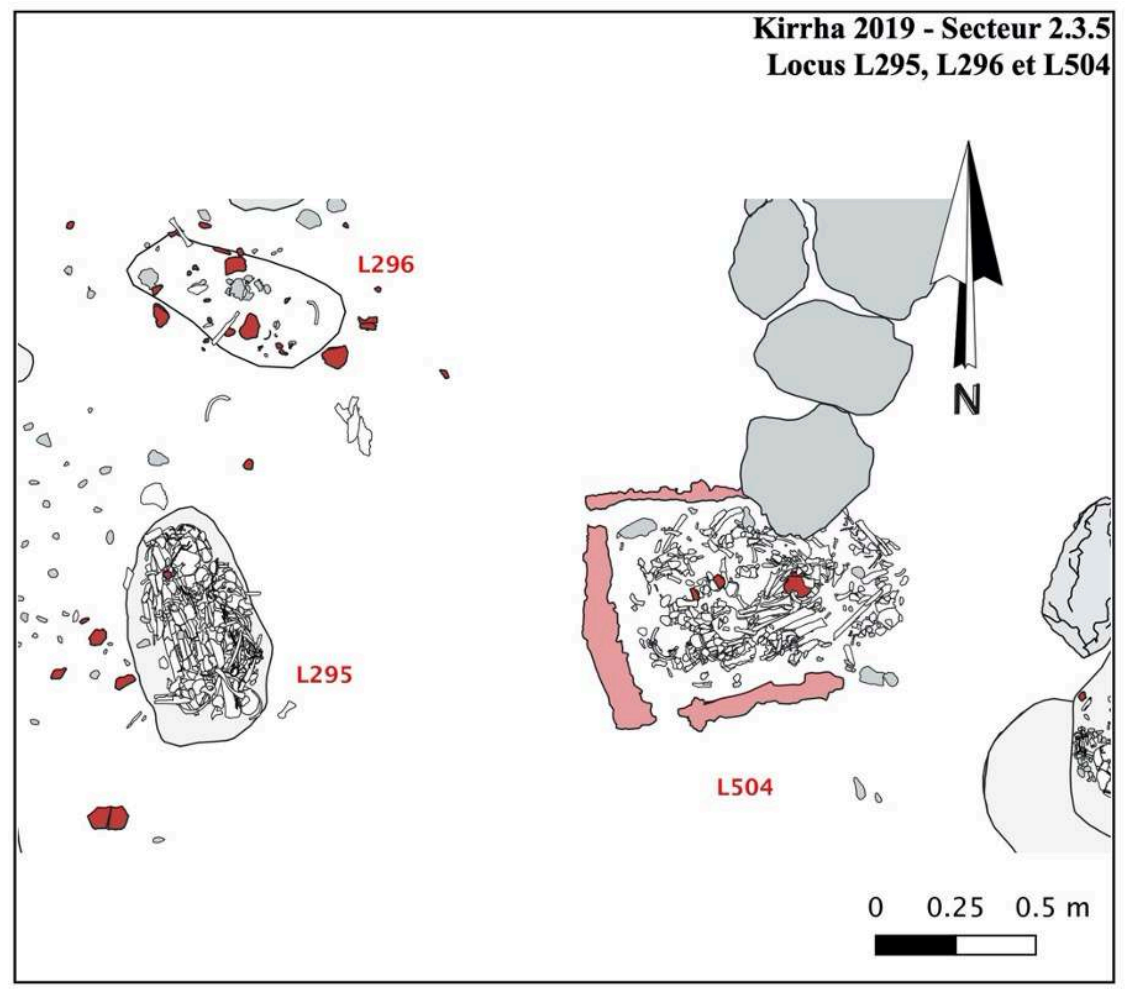

R. Orgeolet, EFA/Mission Kirrha.

81 La fouille de l'US 6163 a mis au jour une poche de sédiment brun foncé avec inclusions de petits cailloutis blancs. Cette poche était orientée Nord-Sud et était très délimitée mesurant 0,72 m sur 0,65 m (Locus L295, fig. 30).

82 Cette fosse étroite accueillait un dépôt secondaire en réduction de deux individus adultes, dont les ossements sont contraints et ajustés aux limites de la fosse (fig. 31). Le comblement de la fosse est limoneux, très meuble de couleur brun-grisâtre sombre, avec quelques galets, de petits fragments de céramique, et de la faune. À partir de la passe 4 apparaissent dans le comblement de grandes inclusions de chaux et quelques charbons.

De manière générale, les ossements a priori bien conservés sont extrêmement friables et se délitent rapidement. 
Fig. 31. L295 - Vue depuis l'Ouest.

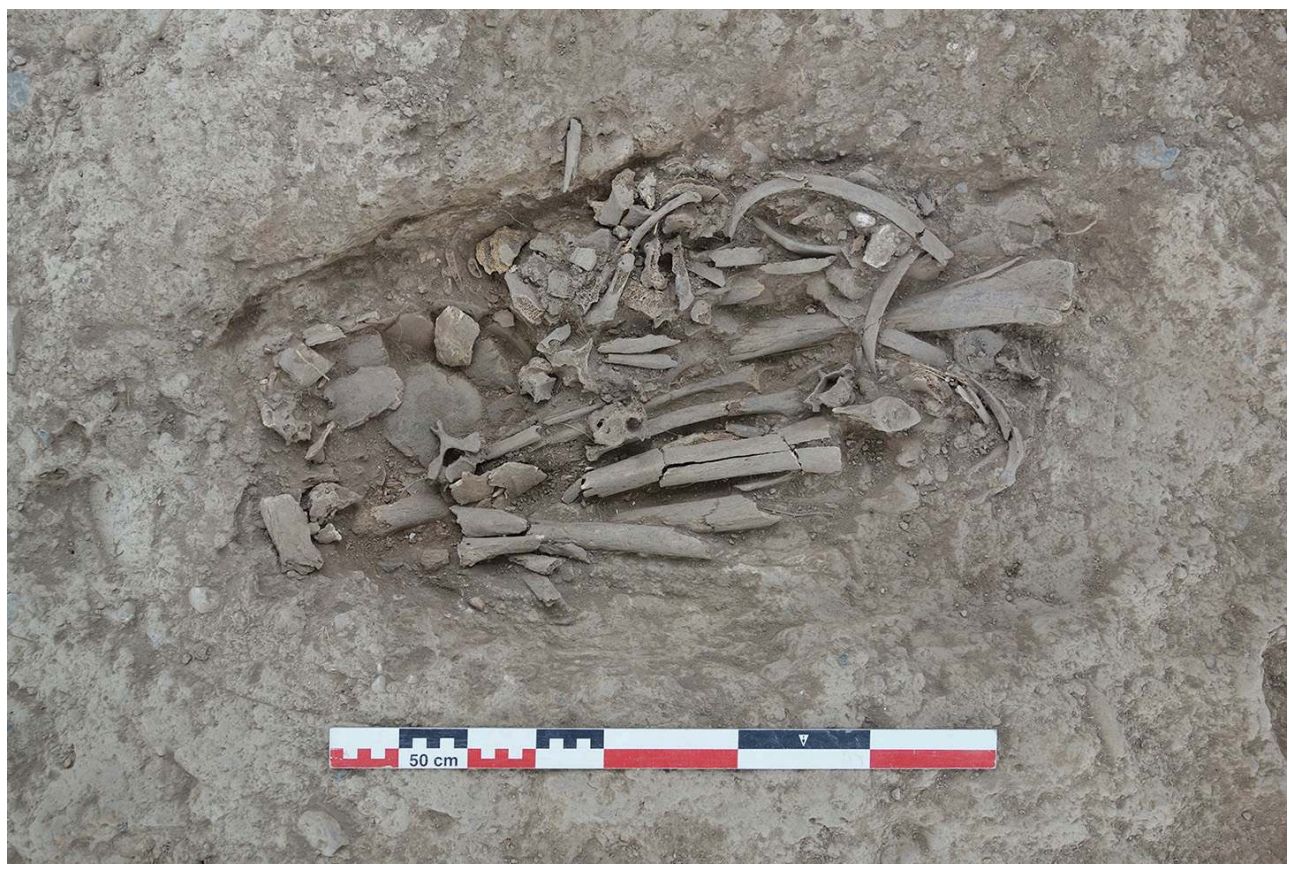

L. Tillard, EFA/Mission Kirrha.

84 Un élément particulièrement remarquable de cette déposition est la volonté d'optimisation de l'espace à l'intérieur de la fosse, qui passe par une certaine mise en scène des ossements, ce qui est notamment observable pour les crânes. L'ajustement et la densité du dépôt sur la passe 2 ont considérablement limité l'effet de percolation des ossements les plus petits.

L307

Le contexte L307 est une fosse orientée Est-Ouest, qui mesure 1,00 m de longueur et $0,86 \mathrm{~m}$ de largeur pour une profondeur totale de $0,50 \mathrm{~m}$. Elle est comblée par l'US 6249 et l'US 6254, cette dernière représentant la terre d'infiltration au-dessus des ossements. De nature limono-argileuse brune, cette couche est homogène, avec des inclusions de terre crue, quelques fragments de céramique et des inclusions de charbons et de galets.

$86 \mathrm{Au}$ fond de cette fosse est déposé un individu adulte en position latérale contractée (fig. 32), reposant sur le côté gauche (cotes supérieures : entre $4,67 \mathrm{~m}$ et $4,76 \mathrm{~m}$ asl). L'individu est orienté Est-Ouest, et le crâne regarde vers le Nord. La dentition indique à première vue un individu âgé. La partie Sud du squelette a été déplacée au cours de la fouille de la première moitié de la fosse. Un bloc de petite dimension a été retrouvé sur le crâne et a endommagé le maxillaire. 
Fig. 32. L307. Vue depuis le Sud.

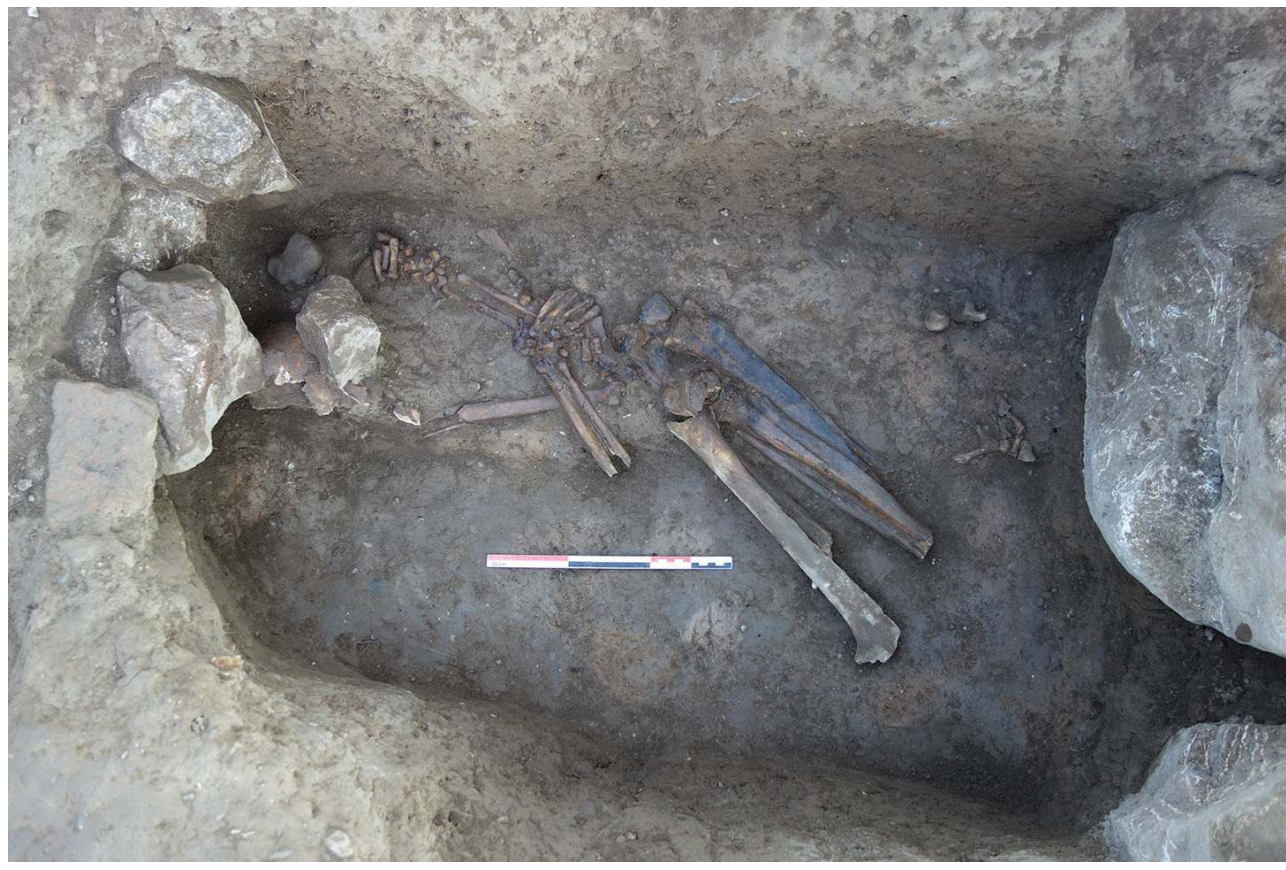

S. Sedlbauer, EFA/Mission Kirrha.

87 Les membres supérieurs sont fléchis et remontent: le bras gauche à la hauteur du crâne, le bras droit au niveau de l'articulation du coude gauche. Les deux mains sont repliées sur elles-mêmes, la droite vers l'Est et la gauche vers le Sud (vers le crâne). Les phalanges distales et médianes de l'index de la main droite ne sont plus en connexion avec le reste des tarses et ont glissés. Probablement en raison de leur position initiale en équilibre sur le radius gauche. Une grande partie des phalanges distales des deux mains n'ont pas été retrouvées. La position contractée des membres inférieurs indique probablement un effet de contrainte ou de maintien. Les pieds sont mal conservés (perdus à la fouille), seuls certains métatarses du pied gauche semblent en place. Dans l'angle de la fosse, juste au-dessus du pied gauche ont été retrouvés deux fragments d'os de faune.

Les deux patellas se sont déplacées probablement au cours de la décomposition. La patella droite a glissé en haut de l'articulation de genou gauche, tandis que la patella gauche a glissé jusque sous le tibia droit. Les deux ont été retrouvées à plat. Si les ossements apparaissent dans un bon état de conservation, ils sont en réalité très friables. La fibula gauche est entièrement écrasée par le tibia et le membre inférieur droit, et particulièrement fragmentée.

La mise à plat des volumes est complète, et les déplacements observés se font tous à l'intérieur du volume initial du corps, ce qui plaide pour un comblement dans un espace colmaté. 
Fig. 33. L309. Localisation du contexte par rapport à L266.

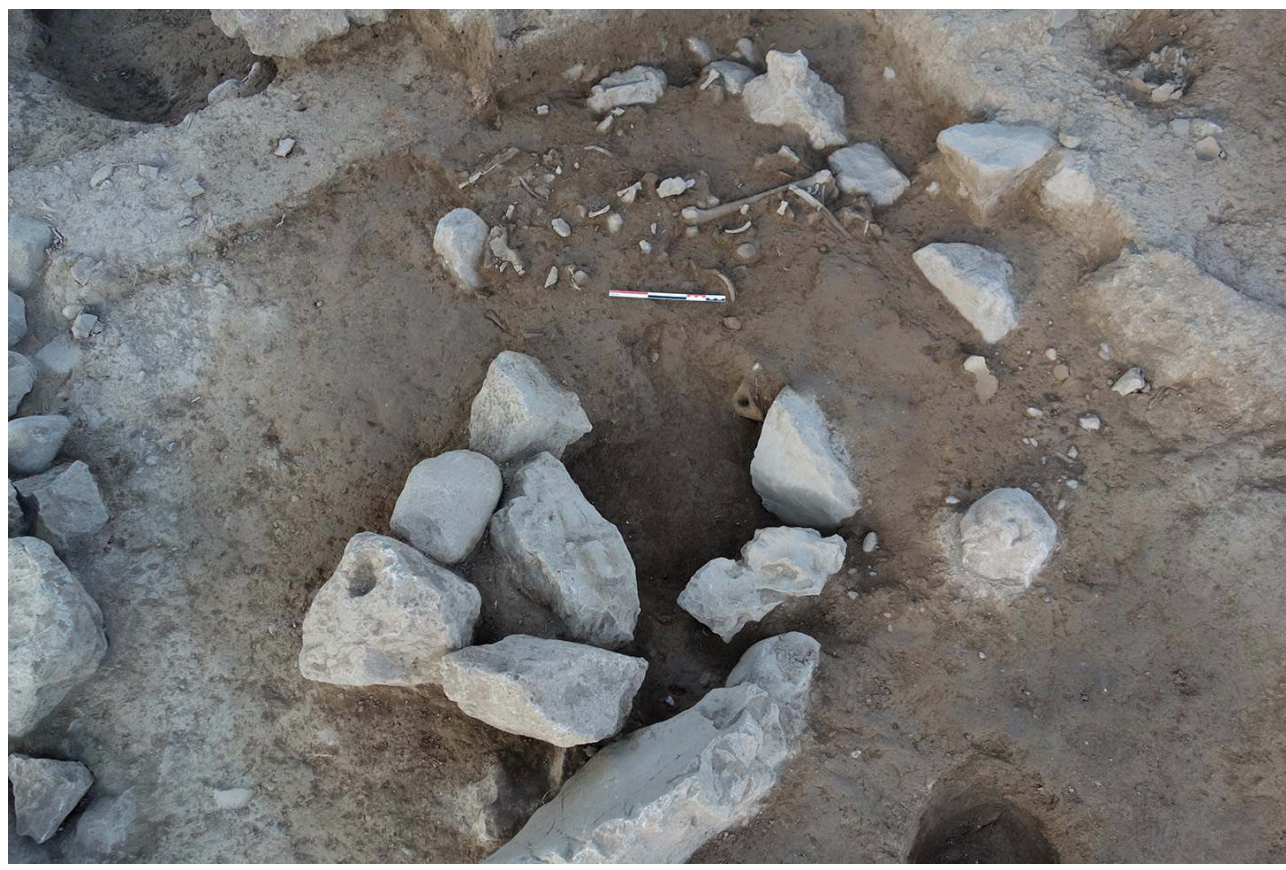

S. Sedlbauer, EFA/Mission Kirrha 0,92 m de largeur, qui a été coupée par l'installation du contexte L266 (fig. 19 et 33). Le comblement de la fosse est brun-jaunâtre, relativement homogène, avec de nombreuses inclusions de galets, de céramique, beaucoup de faunes et trois huitres.

La première passe livre un ensemble d'ossements humains épars, sans organisation visible, auquel se mêlent plusieurs os de faune. La passe 2 a permis de mettre au jour les limites de la fosse de L309, marquées par une large corolle de pierres qui a visiblement été recoupée parL266. Les ossements sont toujours aussi épars, sans logique particulière et mêlés à des éléments de faune. Finalement, la passe $3 \mathrm{a}$ mis au jour de nouveaux ossements éparpillés. On remarque moins de faunes et les ossements humains sont principalement des petits os longs (phalanges, métacarpes, métatarses). Deux os longs (fémur $n^{\circ} 43$ et fibula $n^{\circ} 41$ ) sont orientés vers L266 (partie distale au Nord-Est). Tous deux ont leur partie distale brisée à l'emplacement d'une pierre démontée appartenant à L266, ce qui confirme l'antériorité de L309 sur L266.

Si à l'issue de la passe 3 plus aucun ossement n'était visible, il semble évident que ce contexte continue en profondeur. Malheureusement, le temps a manqué pour en poursuivre la fouille.

L314 
Fig. 34. Plan du Locus L314 dans son environnement.

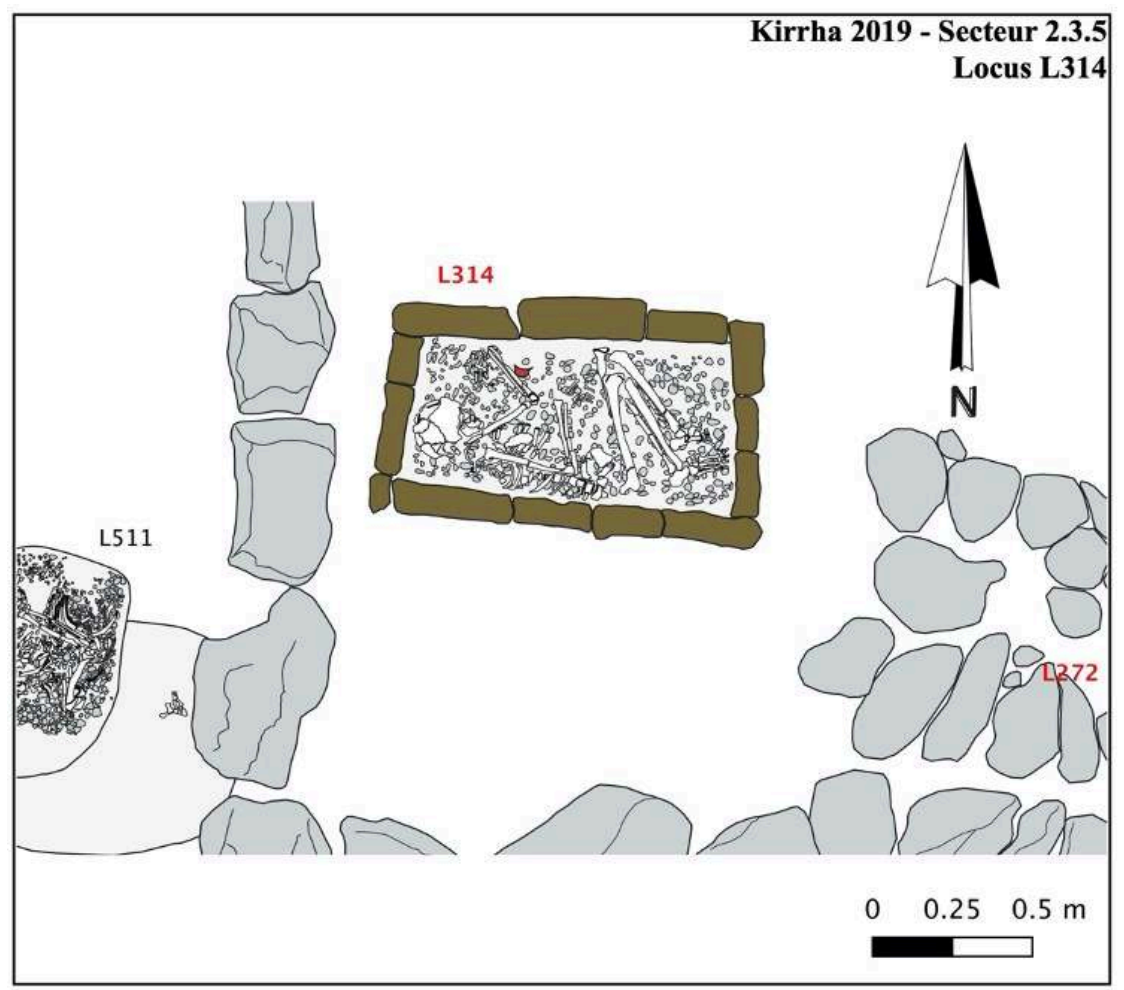

R. Orgeolet, EFA/Mission Kirrha.

Fig. 35. Photographie de la tombe L314 depuis l'Est.

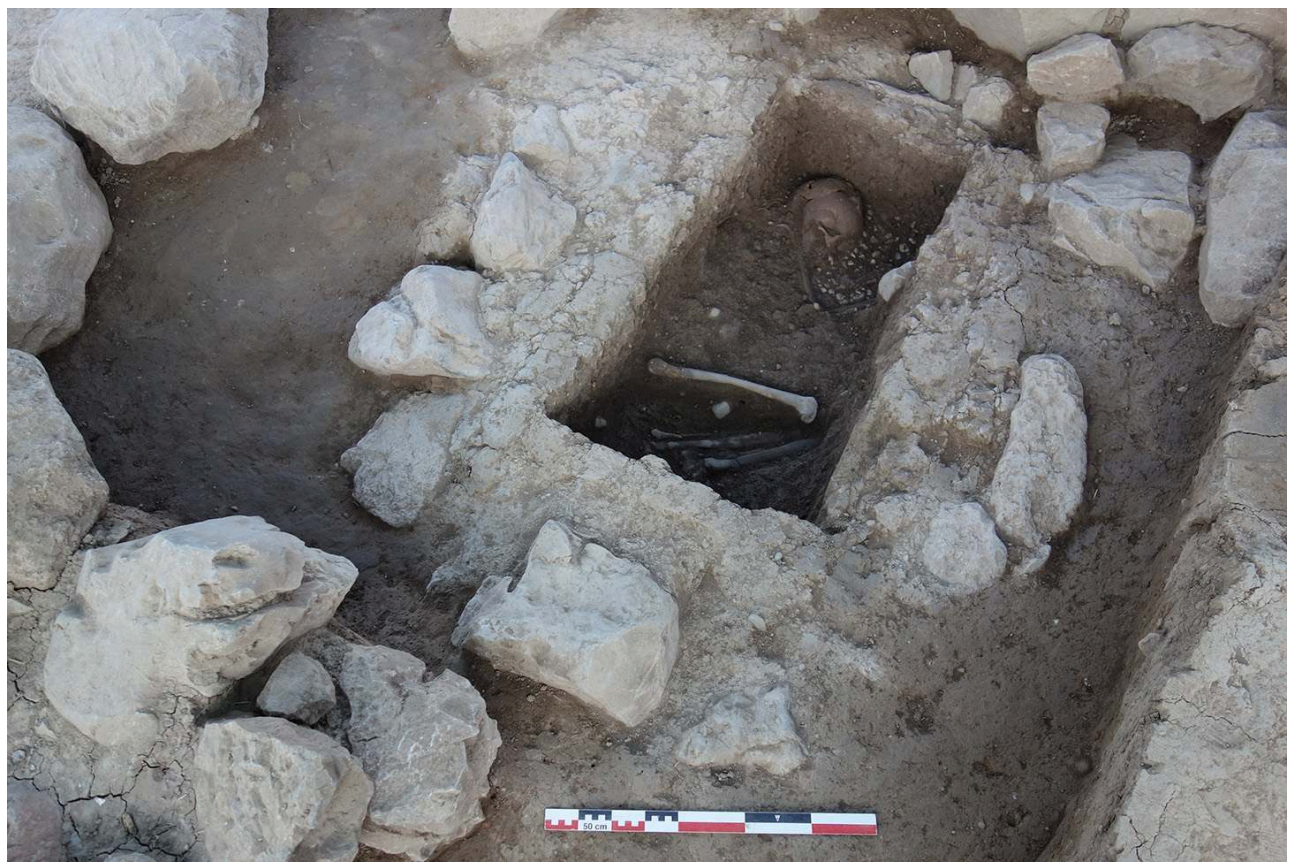

S. Sedlbauer, EFA/Mission Kirrha.

Cette belle tombe à ciste en briques crues est inscrite dans une corolle de pierres de 140 centimètres dans sa plus grande largeur Nord/Sud et sur 170 centimètres dans sa plus grande longueur Est/Ouest (fig. 34 et 35). Un contenant en brique crue a été 
organisé à l'intérieur de ce cercle et délimite un creusement rectangulaire de 101 centimètres de longueur Est/Ouest, 52 centimètres de largeur Nord/Sud et 32 centimètres de profondeur. Nous observons à l'intérieur de celui-ci l'inhumation primaire en espace semi-colmaté (équilibres conservés grâce aux seuls sédiments et/ou aux autres ossements, bouche fermée mais des effondrements et bascules) d'un unique individu (US 6283) reposant sur un lit de galets. Le comblement de cette fosse apparaît à la fouille être un sédiment brun foncé, meuble et argileux.

L'individu est disposé en décubitus latéral gauche orienté Ouest-Est, tête à l'Ouest et face tournée vers le Nord. Le crâne semble pointer vers le bas, le menton rentré et la bouche fermé, position contrainte qui pourrait trouver une origine dans la paroi Ouest ainsi que la légère pente observée sous le crâne. Au niveau de la ceinture scapulaire, la scapula droite repose à l'équilibre contre la paroi Sud et la gauche est trouvé en partie sous celle-ci ainsi que des cervicales et le début du crâne. Les bras sont tous deux pliés au niveau du coude, le bras gauche, levé vers la tête, forme un angle de $90^{\circ}$, tandis que le droit, humérus dans l'axe du corps, forme un angle de $60^{\circ}$. La main gauche est effondrée à l'intérieur de la tombe, présentant sa face dorsale avec des connexions labiles ayant conservées leur intégrité, ce qui nous amène à penser que la main était contrainte contre la paroi Nord et s'est brusquement pliée (effondrement des carpes au démontage des métacarpes) ; la main droite apparaît quant à elle avoir été repliée, des carpes, métacarpes et phalanges proximales présentant leur face dorsale et des phalanges intermédiaires leur face palmaire. En ce qui concerne la partie thoracique, les côtes droites se sont mises à plat, tandis que les gauches ont pu rester à l'équilibre dans l'espace du corps, certaines étant même en connexion étroite avec des vertèbres thoraciques; le sternum a quant à lui glissé à l'intérieur de l'espace thoracique gauche pour se mettre à plat. Au niveau du rachis, les vertèbres sont restées plus ou moins connectées mais un glissement peut être observé au niveau des dernières cervicales et premières thoraciques, les vertèbres ayant suivi la bascule de la tête. Le coxal droit a trouvé un équilibre vertical contre la paroi Sud, alors que le gauche est resté à plat ; par ailleurs la connexion sacro-iliaque droite apparaît déconnectée tandis que la gauche est demeurée étroite et que les symphyses pubiennes présentent toutes deux une proximité restée relativement étroite. Les jambes sont pliées à $70^{\circ}$ au niveau de la ceinture pelvienne et à environ $45^{\circ}$ au niveau des genoux qui reposent contraints contre la paroi Nord; celles-ci ont conservé une logique anatomique à défaut de connexions étroites et le couple tibia/fibula droit s'est mis à plat en dessous du niveau du fémur. A l'observation des pieds, nous notons deux logiques anatomiques : les deux pieds présentent leur face supérieure au niveau des métatarses (jusqu'au cuboïde et naviculaire dans le cas du pied droit), attestant de la mise à plat du pied au moment de la mise en terre, alors qu'une bascule vers la gauche est observée au niveau des chevilles, le pied droit ayant son calcanéus présentant sa face latérale, tandis que les tarses du pied gauche présentent leur face médiale. 
Fig. 36. Photographie de la tombe L504 depuis le Nord.

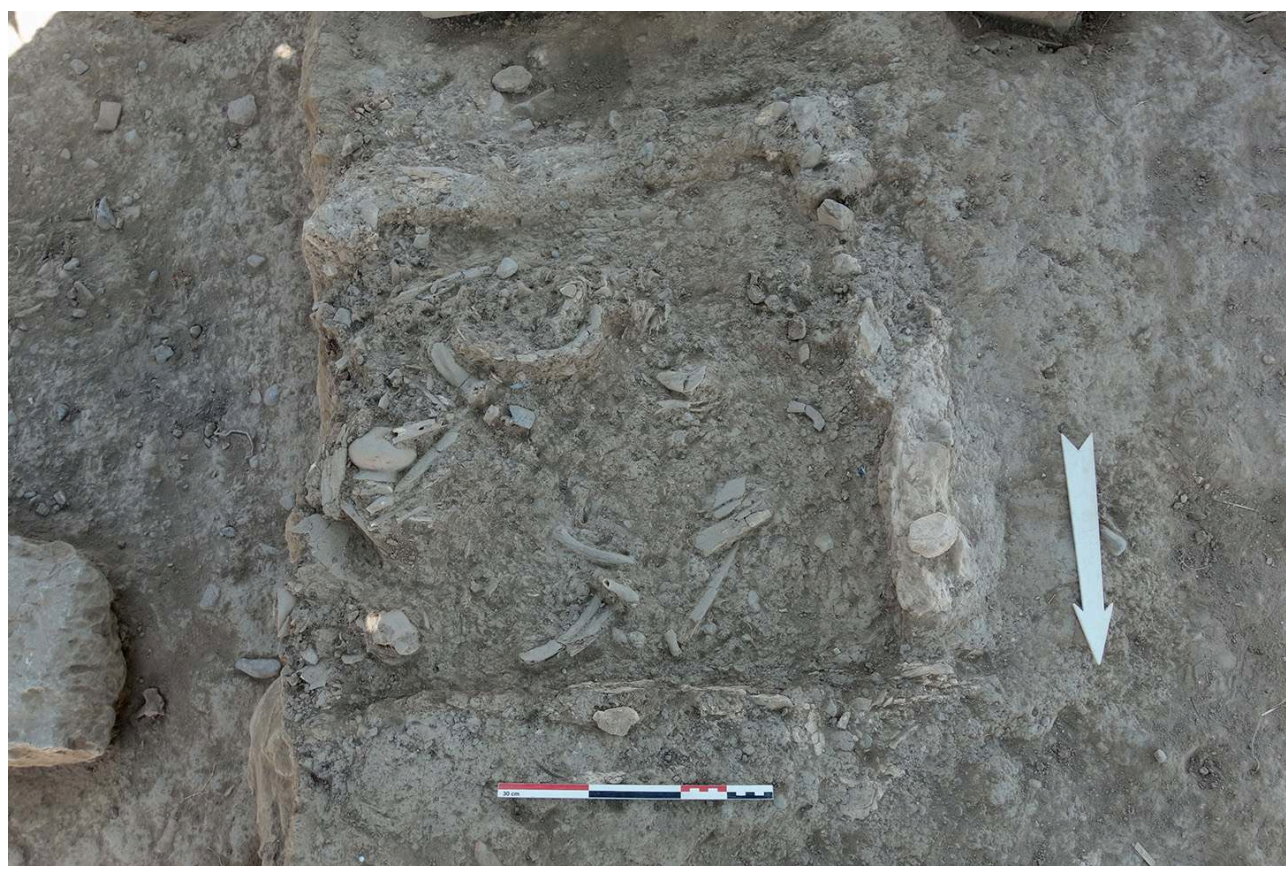

EFA/Mission Kirrha

95 Le locus L504 est un contexte funéraire secondaire dont la fouille avait commencé en 2014, et qui était demeuré pour sa majeure partie intact dans une berme que nous avons fouillée cette année. Il faut en effet adjoindre à l'ensemble dégagé cette année (fig. 36 une petite portion venant le fermer à l'Est (fig. 30).

Ce dépôt était contenu dans un caisson rectangulaire d'environ $77 \times 74 \mathrm{~cm}$ ménageant un espace de 10 à $14 \mathrm{~cm}$ de profondeur, constitué d'un enduit d'argile et de calcite de couleur rosâtre; il est à noter qu'aucune limite orientale avait été détectée en 2014, mais peut-être avait-elle alors échappé à notre vigilance.

Les restes d'au minimum 3 individus dont un immature ont été déposés dans la structure L504. Les os y ont été disposés avec un grand soin, les os longs semblant avoir été disposés de manière à former une sorte de plate-forme quadrangulaire, tel que cela se devine sur le plan (fig. 30). Celle-ci servait de support à d'autres éléments osseux (notamment un crâne), ainsi qu'à un petit vase.

\section{Conclusion}

L'objectif majeur de cette campagne, la purge de la nécropole Ouest, a été atteint. Nous sommes désormais en capacité, une fois l'étude en laboratoire achevée, de pouvoir publier cet important dossier pour l'histoire funéraire de la période transitionnelle en Grèce centrale.

Par ailleurs, la découverte de portions significatives d'architecture HR I sensiblement contemporaines de grandes tombes dans le Secteur 4 est également une nouvelle d'importance, qui méritera une exploration plus poussée lors de la dernière campagne de fouilles, prévue en 2022. Celle-ci visera justement à compléter les données relatives à l'architecture, opération nécessaire avant toute publication. 
INDEX

Thèmes : EFA

lieux https://ark.frantiq.fr/ark:/26678/pcrtU6VuZS5Z9u

chronologie https://ark.frantiq.fr/ark:/26678/pcrtH8P95EucZz, https://ark.frantiq.fr/ark:/ 26678/pcrtGTWPtWn8qu

sujets https://ark.frantiq.fr/ark:/26678/pcrtWegewfitfX, https://ark.frantiq.fr/ark:/26678/ pcrtbptj4SOA1W, https://ark.frantiq.fr/ark:/26678/crtUAQ5MVG24B, https://ark.frantiq.fr/ ark:/26678/pcrt69L0JofMDy, https://ark.frantiq.fr/ark:/26678/pcrtsIm3RuNMGu, https:// ark.frantiq.fr/ark:/26678/pcrtqdNtRi9Tsb, https://ark.frantiq.fr/ark:/26678/pcrtrU7ImEVbLP

Année de l'opération : 2019

\section{AUTEURS}

\section{RAPHAËL ORGEOLET}

Aix Marseille Univ, CNRS, CCJ, Aix-en-Provence, France

ANNE-ZAHRA CHEMSSEDDOHA

Université de Toulouse

MARIE DE JONGHE

Casa de Velázquez

MARIA KATSIMICHA

University of Manchester

RODOLPHE MARTINEZ

Université de Montpellier

ADĖLE VORSANGER

Sorbonne Université

† SIMON SEDLBAUER

Service archéologique Metz Métropole 